\title{
INFORME DEL RECONOCIMIENTO ARQUEOLOGICO REALIZADO EN LA CUENCA DEL RIO CANDELARIA, CAMPECHE
}

Lorenzo Оснол

Emesto Varoas

IIA-UNAM

\section{Introducción}

En el año de 1983, durante los meses de octubre y noviembre, los que suscriben, con la asistencia de Sofia Pincemin, estudiante de la Universidad de París, llevamos a cabo un reconocimiento arqueológico en las cuencas del río Candelaria y dos menores que dan lugar a éste: el San Pedro y el Caribe. El propósito de tal reconocimiento estuvo encaminado a obtener una visión general de la distribución de los asentamientos prehispánicos y la relación que guardan con el paisaje; la localizaciốn de los puntos estratégicos utilizados en el tráfico comercial y la corroboración de la posible exis. tencia de sistemas de camellones utilizados en la príctica de la agricultura intensiva. Aunque se dio prioridad al estudio de las cuencas mencionadas, procuramos incluir algunos asentamientos del interior con el objeto de obtener una visión más amplia de la arqueología de esta área tan poco conocida. Nuestra intención, en cuanto al trabajo de campo toca, ha sido seguir un tanto el enfoque de lo que Armillas (1971) ha denominado "arqueología del paisaje", en tanto que no se limita solamente al estudio de la distribución de los sitios en el paisaje, sino a la comprensión de los esfuerzos que hizo y hace el hombre por modificarlo para su explotación y provecho.

Los reconocimientos estuvieron comprendidos entre Salto Grande y la unión del San Pedro y Caribe; de este punto se hicieron exploraciones sobre ambas cuencas $y$ algunos arroyos que desembocan en estas. Desde las márgenes hacia el interior, se tomaron en cuenta 
sitios que no estuvieran a mayor distancia de unos diez kilómetros, aunque algunas veces sobrepasamos tal medida. Para el objeto, a través del estudio de la fotografía aérea, con posibilidades limitadas o nulas para la localización de asentamientos en esta área, intentamos detectar pasos francos que pudieron ser utilizados para la comunicación, pero también nos sirvió para identificar algunos as. pectos agrícolas señalados con anterioridad por otros investigadores. Al mismo tiempo, nos fue de utilidad para desplazarnos en el campo, ya que las cartas geográficas existentes no son muy confiables. Ambas, sin embargo, utilizadas de manera complementaria constituyen una herramienta de gran valor para los objetivos que nos habíamos propuesto realizar. De esta manera, en ciertos casos, pudimos elaborar un catálogo de sitios con sus características y puntes que pudieron ser relevantes en las comunicaciones y el comercio. En otros sólo hemos logrado poner los datos que nos proporcionaron los informantes, ya que por las condiciones climáticas nos fue imposible visitarlos. Asimismo se hicieron recolecciones de superficie cuando fue factible, aunque para la época en que se llevaron a cabo los trabajos las posibilidades fueron minimas a causa de lo crecido de los pastos; aspecto que incidió en lo limitado de los levantamientos topográficos, pues no siempre fue posible realizarios (Láminas I y II). En este sentido, se hicieron croquis con brújula y cinta $y$, en algunos casos, con teodolito. Las condiciones climáticas, si bien afectaron ciertos puntos que se intentaba cubrir, no limitaron los propúcitos generales de nuestro reconocimiento $y$, de hecho, obtuvimos suficiente información para plantear un acercamiento a la arqueologia de la cuenca del Candelaria (Mapa),

De este modo, pensamos que, con los datos recabados durante el trabajo de campo, estamos en posibilidades de sugerir investigaciones de problemas específicos en determinados sitios. En este informe pues, aunque discutiremos algunos puntos sobresalientes, pretendemos dar a conocer la información obtenida a partir de dichos trabajos $y$, por tanto, será meramente descriptivo, sin entrar en detalles particulares que, por otro lado, habrán de escapar.

\section{La provincia de Acalán y la cuenca del Candelaria}

Las Tierras Bajas Noroccidentales del área maya - ocupadas por los chontales-, jugaron papel relevante en el aspecto económico du- 
rante el periodo Postelísico. Xicalango, Potonchán, Tixchel e Itzamkanac aparecen en las fuentes históricas como importantes puertos de intercambio, especialmente los dos primeros y el último. De Xicalango algo hemos averiguado acerea de su probable ubicación (Cfr. Ochoa y Vargas, 1979); del segundo hemos escrito ciertas consideraciones con base en la exploración del área en que se supone que estuvo bcalizado y más tarde se fundara Santa Maria de la Victoria, según se infiere del mapa circular de Melchor de Alfaro Santa Cruz confrontado con otro del siglo xrx elabo. rado por Don Tomás de Avendaño (Ochoa y Vargas, Ms.). El lugar que tal vez corresponda a Tixchel ha recibido atención por parte de Ruz Lhuillier (1969), mientras que de Itzamkanac, que se presume estuvo en la provincia de Acalán, se han ocupado Scholes y Roys (1968) y Piña Chán y Pavón Abreu (1959) que lo identifican con El Tigre. El pretender ubicar la situación geográfica de este último, fuera de las implicaciones relacionadas con la muerte de Cuauhtémoc, sería clave para poder conocer y entender las relaciones que guardó con otras áreas, las características culturales y el porqué de su importancia económica, a efecto de intentar una explicación de los procesos histórico-culturales ahí ocurridos. Todo ello sólo sería factible abordarlo a través del estudio y análisis de las fuentes históricas, la arqueología y la geografia del área, apoyados en estudios lingüisticos y etnográficos.

Sabemos que por Itramkanac pasó Hemán Cortés en su expedición a las Hibueras; que más tarde Alonso Dávila siguiendo en ciertos casos las huellas de aquél llegó a la provincia de Acalán en su viaje a Champotón. Sin embargo, ni uno ni otro, evidentemente, fueron por rutas muy transitadas o conocidas, toda vez que en sus recorridos no encontraron viajeros o comerciantes en el primer tramo del trayecto, con quienes sí toparon posteriormente; aunque sabemos que a Cortés, durante su estancia en Cupilcon, le fueron proporcionados mapas de tales regiones, no parece haberlos utilizado, ya que señalaban derroteros por vias acuáticas (Cortés, 1969).

En este sentido, a la llamada provincia de Acalán llegaban diversas rutas, fluviales y terrestres, una de las cuales era la más importante como via de tránsito y tráfico comercial: el río Candelaria. Efectivamente, varios documentos aś lo atestiguan y era la que unia a Itzamkanac con el interior, para llegar a los puertos de Nito y Naco en Honduras, así como con Xilacango, Tixchel y otros puntos de la costa del Golfo de México. Pero también caminos terrestres conducian de aquel puerto a Mazatlán, capital de los 
cehaches, según relata Fernández de Oviedo; el mismo Hernán Cortés entró a Itzamkanac por tierra firme, con lo cual se pone de relieve su importancia como puerto de intercambio.

Por otra parte, de interés primordial para otros aspectos de esta cuenca es el hecho de haberse apuntado la posible existencia de lo que se ha interpretado como camellones de cultivo, o campos levantados de carácter agrícola, así como canales de riego (líminas III y IV), además de considerarse otras, como el transporte (Siemens y Puleston, 1972, Adams et al., 1981; Marcus, 1983). Asimis. mo, basado en las primeras noticias sobre el particular Eric Thompson (1974) interpretó dichos canales como fuentes de abastecimiento, al pensar que habian sido hechos con el propósito de crear nichos ecológicos artificiales, asunto que trató de fundamentar por medio de un modelo de analogía etnográfica. Por lo pronto, sabemos que en los camellones no se han encontrado evidencias de plantas cultivadas en los análisis que se han efectuado en los restos recuperados ahi, y que hay indicios que nos llevan a asegurar que por lo menos algunos de los canales detectados son muy tardios (siglo $\mathrm{xxx}$ ), según nuestra información de campo $\mathrm{y}$ las investigaciones de Luis Millet (1984). Este autor ha averiguado que varios canales de la zona de Campeche se abrieron con el proposito de sacar madera y el palo de tinte de manera más expedita a los ríos. Trabajos realizados en posibles camellones de otras zonas, no aportan pruebas contundentes que demuestren la función agricola de esas supuestas construcciones, aunque no puede desecharse tal idea (Cfr. Turner II y Harrison, eds, 1983).

Ahora bien, queremos llamar la atención de que muchos de los tenidos como canales prehispánicos son de reciente creación y se usaron como medio de transporte y se continúa haciendo uso de éstos con el mismo fin; pero que acaso algunos de los llamados camellenes pueden no ser obras artificiales sino formaciones materiales que, en algún momento, se aprovecharon como lugares de cultivo por las favorables condiciones que ofrecian. Con anterioridad, uno excavado en la Chontalpa asi lo refleja (Jiménez, 1984).

\section{El reconocimiento}

El área de reconocimiento se circunscribe al municipio de EI Carmen, Campeche y el poblado que sirvió de punto de referencia es Candelaria, enclavado sobre la margen derecha del río del mis- 
mo nombre. Para fines prácticos de este informe vamos a dividin la localización de los sitios en siete secciones:

1. Candelaria-Salto Grande.

2. Candelaria-Boca de Santa Isabel.

3. río Caribe

4. rio San Pedro

5. Candelaria-EI Naranjo

6. Colonia Estado de México

7. Candelaria-Miguel Alemán

\section{Candelaria-Salto Grande}

Dentro de esta sección incluimos dos sitios; uno ubicado sobre la margen izquierda del Candelaria y el otro tierra adentro de este rio, sin que ello implique que sean los únicos.

Rancho Santo Domingo. Localizado unos diez kilometros río aba. jo de la población de Candelaria, frente a unos rápidos conocidos como "Salto Grande". Al parecer con este último nombre se conoce en la literatura (Cfr. Andrews, 1943: 47 y mapa; Scholes y Roys, 1958), aunque no se anota ninguna particularidad del mismo. Hoy dia se encuentra en el rancho del mismo nombre propiedad del Sr. Elias de la Cruz. Está ubicado a unos $500 \mathrm{mts}$. de la margen izquierda del río, sobre unas pequeñas lomas de pendiente suave desde donde se dominan el río y los rápidos. Este punto constituye y continuia una parada obligatoria para continuar la navegación en cualquier dirección, por lo que puede considerarse como un emplazamiento estratégico para el control del tráfico (figura 1) (Lúmina V).

Actualmente el medio se encuentra bastante alterado a causa de la déforestación y sólo se aprecian acahuales y algunos ejemplares de huano, jobo, chacá y palma real, a menudo cubriendo los montículos mayores, si bien todo el terreno está dedicado al pas. toreo de ganado vacuno. Entre el asentamiento y el río existe un recodo que pudo haber servido de puerto $\mathrm{y}$ aunque actualmente se encuentra cubierto por vegetación acuática los montículos mayores están enclavados hacia este punto.

El sitio en cuestión se compone de una zona habitacional dis. persa y de un pequeño centro con una plaza bastante amplia y abierta hacia el sureste, rematada en el tado poniente por un montículo de unos seis metros de altura desde donde se domina el ría 
Aunque por desgracia dos de los monticulos mayores tienen pozos de saqueo, no fue posible recuperar ningún tipo de material, aunque sí nos percatamos que en las construcciones se utilizó piedra y mortero. En total se aprecian siete montículos mayores rodeados por unas 15620 hectáreas de lo que probablemente constituye el área habitacional, con excepción del lado noreste que se encuentra formado por bajos y pantanos que, como dijimos, acaso en la época prehispánica formaba la entrada al sitio desde el río.

Palmitas o Nueva Esperanza. Este sitio se reconoce indistintamente con cualquiera de estos nombres y se encuentra dentro de los terrenos del Sr. Atenor Garrido. Dispersos por una superficie de unas tres o cuatro hectáreas, pueden apreciarse restos de poco más de diez montículos, imposibles de apreciar en su totalidad a causa de lo crecido que estín los pastizales para esa época. Se trata de un conjunto cuyos montículos principales forman una especie de plaza abierta al noroeste. A más o menos medio kilómetro en dirección suroeste existe un manantial permanente que corre hacia el noreste $y$, aparentemente, llega hasta una laguna en la cual se aprecia la pesca (Figura 2).

Al oriente del conjunto principal se distribuyen varias docenas de monticulos habitacionales, por unas 10 ó 15 hectáreas enclavadas a un nivel más bajo, excepto una gran plataforma localizada al noreste del conjunto. Aunque el medio se encuentra bastante alterado a causa de la ganadería extensiva, se nos informó que hace algunos años todavía se conservaba una alta selva tropical en donde el puerco de monte, venado, tapir, sarahuato y otron animales que junto con el manantial y la laguna pudieron ser foco de atracción para que se diera tal asentamiento. Pudimos apreciar en un pozo de saqueo que se utilizó la piedra como material de construcción y la recuperación de dos tiestos con pinturas de color anaranjado rojizo, nos hacen pensar que la ocupación parece corresponder al periodo Clásico.

\section{Candelaria-Boca de Santa Isabel}

Coahuila. Se encuentra sobre la margen izquierda del río, cerca de la linea del tren y de la carretera que comunica el poblado de Candelaria con las colonias de reciente creación. Está en terrenos del $\mathrm{Sr}$. Carlos Martinez. En este sitio se dificulta apreciar la distribución de los montículos ya que varios fueron arrasados con ma- 
quinaria, aunque quedan restos de cuatro de ellos, visibles dentro de los pastizales dedicados a la práctica de la ganadería extensiva. El sistema de construcción parece haber consistido en amontonamiento de tierra para formar las plataformas sin que se pueda apreciar ningún tipo de recubrimiento. El material cerámico que se obtuvo es doméstico, pero posiblemente podría pertenecer al Clásico.

Venustiano Carranza. Se localiza también sobre la margen izquierda del río, frente a un ojo de agua y relativamente cerca de la población del mismo nombre. Es un sitio fundamentalmente habitacional ubicado sobre unas suaves colinas, pero a causa de las condiciones de los pastizales es difícil establecer su área de ocupación. Entre este sitio y el anterior nos fueron reportados otros dos asentamientos con caracteristicas similares que por las condiciones del terreno y del clima no fue posible visitarlos (Lámina VI).

Cabe destacar que sobre ese tramo hemos inspeccionado algunos de los canales, reportados con anterioridad por otros autores, como parte del supuesto sistema de riego del Candelaria; sin embargo, corresponden a vías acuáticas recientes abiertas por los pobladores para llegar a sus milpas o bien para entrar a sus ranchos desde el rio.

Boca del Cuervo. Se ubica río arriba del anterior sobre la margen izquierda y relativamente cerca de la orilla del rio, sobre un lomerio. Está inmediatamente pasando una serie de meandros que forman el Candelaria.

En cuanto a su distribución podemos decir que las construcciones se ubicaron sobre la parte alta de una elevación natural, en donde se formó un pequeño centro rodeado de pequeñas plataformas habitacionales.

Las Delicias. Al igual que los anteriores, se encuentra en la margen izquierda del río, casi inmediatamente después de Boca del Cuervo. Es un sitio habitacional, también ubicado sobre unas pequeñas elevaciones, en donde destaca lo que podemos considerar un centro principal de dimensiones modestas. La extensión total del asentamiento es de unas diez hectáreas, pero cabe señalar que tanto en la fotografia aérea como en el terreno se aprecian dos "canales" que se internan hacia las colinas y que desde estos sitios se domina una gran sección del rio. Asimismo, destacaremos que sobre la margen 
derecha, río arriba, se ven huellas de por lo menos otros seis "canales", que como en los casos anteriores no están excavados en la tierra sino que han sido abiertos retirando la vegetación acuática.

Acahual. Enclavado en la margen izquierda del río, sobre terrenos relativamente bajos, inundables. Aqui, como en prácticamente toda la región el paisaje original está sumamente alterado. Debido a que los terrenos se encontraban inundados no fue posible hacer un reconocimiento minucioso. Se trata de un asentamiento habitacional de acuerdo al tipo de plataformas encontradas que son bajas y de dimensiones restringidas. Por las condiciones del terreno no se puede saber ni la extensión ni la época de ocupación del lugar. Finalmente, queremos agregar que en la margen derecha se notan trazas de canales con las mismas earacterísticas de los mencionados antes.

Rancho los cuyos. Este sitio había sido reportado con anterioridad por W. Andrews con el nombre de El Naranjal (Figura 3). En la actualidad esos terrenos son propiedad privada. Está localizado estratégicamente sobre una explanada desde donde se domina el río Se trata de un sitio habitacional distribuido anárquicamente; pues se trató de aprovechar las partes altas para ubicar las plataformas. Dado que se han abierto pozos de saqueo, se apreció que en los basamentos se utilizb piedra como material de construcción. Ahora bien, aun cuando como en los sitios anteriores los terrenos estín dedicados a la ganaderia, en los alrededores se aprecian manchas de selva baja.

Ruinas de Pablo Garcia. El acceso a este lugar se puede llevar a cabo por una desviación que existe hacia la colina del mismo nom. bre desde la carretera Candelaria-Colonia Estado de México.

El sitio en cuestión se localiza sobre la margen izquierda y al poniente de El Tigre y relativamente retirado de la orilla del rio. Tanto estos vestigios como los de El Tigre se unen por medio de una calzada de unos $250 \mathrm{mts}$. de longitud y unos $10 \mathrm{mts}$. de ancho en promedio, con toda seguridad El Tigre y P. Garcia son sitios contemporáneos. Desgraciadamente carecemos de evidencias sobre las ocupaciones de este sitio, pero la calzada en cuestión salvaba unon pantanos que impiden el acceso de un lugar al otro (Lámina VII).

Este asentarniento está enclavado sobre un terreno bastante sinuoso, por los afloramientos de roca caliza; en determinados lugares se hicieron relienos cerca de los pantanos en donde se nota que ubjcaron algunas de las estructuras cuya función es imposible determi- 
nar. Asimismo, pudimos apreciar que en algunos afloramientos de roca hay claras huellas de corte por lo que es probable que de esta zona se hubiera extraído material para las construcciones, no sólo de éste sino de las de EI Tigre. Finalmente, cabe señalar que aun cuando desconocemos la extensión total del asentamiento, éste puede llegar a unas 50 hectáreas con un centro que tiene edificios de 8 a 10 metros de altura, plazas, plataformas, todos fabricados con piedra. La destrucción de que ha sido objeto el lugar y la maleza nos impidieron llevar a cabo cualquier reconocimiento detallado. Pero, hipotéticamente, podemos apuntar que su estudio dará mucha información para explicar El Tigre.

El Tigre. Sobre unos lomeríos de origen calcáreo, este asentamiento se extiende por algo más de cinco kilómetros cuadrados y aunque el centro y edificios principales se encuentran dentro del ejido del mismo nombre, en determinadas secciones se encuentran en el ejido Pablo Garcia.

En esta ocasión sólo fue posible llevar a cabo un reconocimiento general del sitio debido a que los pastizales dedicados a la ganadería extensiva estaban sumamente crecidos (Láminas I y II). De todas formas se realizó el croquis del Jugar en su parte principal. Hoy dia el paisaje se encuentra sumamente alterado a causa de la tala inmoderada, no obstante aún quedan ejemplares de la flora $y$ de la fauna de la región. De la flora es posible apreciar algunas palmas de huano, así como jabin, jobo, chico-zapote, guásimo, ramón, cantemó y cedro principalmente. Sin que sean abundantes, por ahí se encuentran venado, puerco de monte, tigrillo, onzas, comadrejas, tepescuintle $y$, de manera más común armadillo. Aves como garzas, chachalacas, patos y tucanes $y$ en el río la pesca es abundante: mojarra, bobo, tenguayaca, macabil, zacatera, robalo, asi como tortugas de varias clases; no faltan por supuesto, las víboras de cas. cabel, coralillo y nauyaca.

Por otra parte, los habitantes del ejido aprovechan la miel silvestre que juega papel destacado en la economía y algunos frutos silvestres como el chicozapote y el jobo. La crianza de cerdos y aves de corral también forman renglón sobresaliente en la economia familiar; aún cuando el principal apoyo lo constituye la ganaderia y en menor grado la agricultura. En ésta, el maiz y el frujol constituyen una buena fuente de abastecimiento, si bien el cultivo de la chigua provee una entrada económica importante ya que se saca al mercado 
y se cotiza a un precio muy alto. De la semilla de esta calabaza se extrae aceite, por lo que es muy solicitada en el mercado nacional.

Ahora bien, el haber sobresalido este sitio en la época prehispánica tiene su explicación en su enclave estratégico, sobre unas lomas desde donde se domina parte importante del rio; una ensenada bastante protegida que pudo servir de puerto, la existencia de materias primas y el río mismo que fue la via de comunicación más expedita por la cual se puede alcanzar tanto la costa como el interior de las tierras bajas mayas (Lámina VIII).

Destacan en el asentamiento un centro principal, el área habita. cional con algunos conjuntos menores y una calzada (Láminas VII y IX). Fuera de esta zona, en la margen opuesta se aprecia un gran canal que ha sido objeto de distintas interpretaciones, así como una serie de elevaciones regulares (Límina III) que han sido explicadas como áreas destinadas a la práctica del cultivo intensivo.

Dentro del conjunto principal destacan algunos basamentos piramidales, que sobrepasan los 20 metros de altura, plataformas, posibles "palacios", casas que acaso pertenecieron a la élite, altares, plazas y quiź́s una estructura para la práctica del juego de pelota (Figura 4). Todo este centro se encuentra rodeado por cientos de estructuras no fáciles de identificar en cuanto a su función, si bien en su mayoría parecen haber sido de habitación. En algunos puntos del área habitacional, sin embargo, se aprecian conjuntos de edificios de cierta importancia en relación a los basamentos que los rodean. En éstos pueden apreciarse plataformas para sostener templos y tal vez casas de la gente principal, arregladas de tal modo que en ciertos casos forman pequeñas plazas. De la misma manera, por la distribución y concentración de materiales en determinados puntos, es posible insinuar que existen talleres destinados al trabajo de la piedra.

En cuanto a la calzada, como apuntamos, fue construida sobre terrenos bajos, pantanosos, con el objeto de unir El Tigre con el conjunto que se localiza en el ejido Pablo Garcia. Asimismo, debemos apuntar que ésta se localiza en la parte mejor protegida del sitio, en donde se forman una suerte de puerto natural, lo que le da una ubicación estratégica. Dicha calzada está cortada en dife. rentes puntos por medio de pequeños canales (entradas), revestidos de piedra, con lo cual, si bien se facilitaba también se controlaba la entrada de las pequeñas embarcaciones que pasaban del río hasta puntos muy cercanos al centro principal; detalle que no es posible detectar a través de la fotografia aérea. No es aventurado pues, 
plantear que tanto el emplazamiento del sitio desde donde se domina una gran parte del rio, como de la calzada con sus canales y la disposición natural de la ensenada. hicieran de El Tigre un puerto bastante funcional para el comercio. Aún hoy en dia, la única vía expedita para salir a la costa o alcanzar puntos de tierra adentro es el río.

Como señalamos, en El Tigre se han reportado algunas formas de explotación intensiva de la agricultura por medio de canales y camellones. Por lo tanto, parte de nuestro reconocimiento llevaba como objetivo la descripción de éstos. Y en este sentido la expe riencia ha sido muy interesante, ya que por la época en que rea. lizamos los trabajos, final de la estación de lluvias, esperábamos encontrar los camellones tal y como posiblemente eran aprovechados La sorpresa, sin embargo, fue que estaban casi un metro bajo el nivel de las aguas. El reconocimiento de esta parte lo hicimos en cayuco, ya que era imposible caminar por ellos, como lo habiamos hecho en mayo de 1978. Lo importante es que se nos informó que las aguas se mantienen a un nivel alto desde los meses de septiem. bre-octubre hasta marzo-abril; esto es casi la mitad del año, lo cual nos hace pensar en una reconsideración de esta posibilidad agricola. Asimismo, agregaremos que la construcción de unos de los canales más importantes que se pueden observar frente a El Tigre, en apariencia, es de reciente apertura, acaso del siglo xtx, con lo cual estaríamos reforzando algo de lo apuntado por Millet que ha dedicado aigunos trabajos a este asunto.

Finalmente tenemos que apuntar que tal como ya lo habian hecho Piña Chán y Pavón Abreu, hay una importante ocupación en el Postclásico, pero también en el Clísico, como señalan Puieston y Siemens. Sin embargo, las ocupaciones del lugar comienzan en el Preclásico Superior, aunque por lo pronto desconocemos en qué momentos se da el auge del sitio.

\section{Río Caribe}

Boca de Santa Isabel. Se localiza cerca de la confluencia de los ríos Caribe y San Pedro, aunque el acceso se facilita desde el primero. Este sitio se encuentra en terrenos privados que colindan con los del ejido de El Tigre. Actualmente se encuentran dedicados a la ganaderia, si bien por ahí $s$ aprecia bastante huano y vegetación de matorral. Se trata de un sitio habitacional, aunque existen al- 
gunos basamentos que posiblemente tuvieron otra función. No se puede apreciar una distribución precisa de las construcciones ni tampoco del material de construcción.

Cerro de los Muertos. Ubicado en la margen izquierda del río Caribe, sobre unas elevaciones. Su localización se dificulta debido a que esta sección del río está cubierta de árboles grandes como ramón, chacá, jobo, cedro y jabin principalmente. En la actualidad los terrenos son propiedad del Sr. C. Cabrera Hernández (Lámina $\mathrm{X})$.

Las elevaciones fueron niveladas a diferentes alturas y se cons. truyeron varios grupos de edificios. Sin embargo, el monte bajo impidió llevar a cabo un recuento exacto de todas las estructuras (Figura 5), especialmente por la abundancia de nauyacas que en esta época del año hacen peligroso el reconocimiento. A pesar de ello, con lo visitado, nos percatamos de la monumentalidad de los edificios que en términos generales se encuentran muy bien conservados, con excepción de algunos pozos de saqueo. Visitamos tres de los grupos, uno de carácter habitacional, otro cuyos edificios más altor tienen unos 15 metros de altura y corresponden al centro políticoreligioso y el tercero corresponde a zonas terraceadas, aunque exis. ten algunas estructuras más en la parte superior.

La zona habitacional se encuentra bien conservada y el terreno está destinado al cultivo de maiz Se compone de plataformas bajas $y$ algunos monticulos de cierta altura que forman gripos y plazas. En la zona politico-religioso los edificios forman en un caso una plaza cerrada y en otro una abierta. Está ubicado el conjunto sobre unas elevaciones naturales y son de pendiente bastante pro. nunciada. El sistema de construcción es de piedra con mortero. Destacan siete estructuras y desde la parte superior de éstas puede dominarse el rio hasta El Tigre y Santa Clara, sitio que describiremos adelante. Hacia el noreste se localiza una zona terraceała, en donde pudimos apreciar que habia material cerimico en superficie del Clásico tardio. Ahi existen restos de plataformas pequeñas y más arriba se localizan otras construcciones de mayores dimensioves. En la literatura este lugar no aparece reportado, si bien había sido señalado por Scholes y Roys. De todos modos, ignoramos quién le puso el nombre de Cerro de los Muertos y desde cuándo, aunque todo parece indicar que asi se le puso porque ahi se encontraron restos de huesos humanos. La poca cerámica que se pudo apreciar nos da fechas de Clásico tardio-Clásico terminal. 
Santa Clara. También se extiende sobre la margen izquierda del Caribe y sobre unas elevaciones suaves, desde donde se domina gran parte del río. Hasta ahi, hemos observado que prácticamente todos los sitios fueron ubicados tratando de tener un dominio de las vias de comunicación. El paisaje estí sumamente alterado debido a que los terrenos están dedicados a la ganadería. Es un sitio bastante extenso, por lo menos entre la zona de monumentos y el área habitacional cubren poco más de 50 hectáreas. Para el efecto parece ser que las lomas fueron niveladas, especialmente en la zona que corresponde a las estructuras mayores que miden unos 10 metros de altura (Láminas XI y XII).

En este lugar se aprecian varios conjuntos, uno de ellos formado por cinco estructuras, cuatro que corresponden a plataformas y una estructura piramidal que conforman un espacio abierto. Otro grupo está delimitado por una gran plataforma que sostiene un basamento posiblemente piramidal y una pequeña estructura. Otra plataforma rectangular tiene tres montículos (Figura 6). El conjunto principal está conformado por estos tres grupos, aunque existen otros montículos grandes fuera de esta zona, localizados en determinados puntos de la parte habitacional que prácticamente rodea el sitio, desde la orilla del río hasta cerca de un kilómetro tierra adentro.

Respecto al sistema de construcción podemos decir que es bas. tante similar al que apreciamos en El Tigre y Cerro de los Muertos; en cuanto a la cronología, de acuerdo a unos cuantos tiestos que se pudieron recuperar, éstos son de anaranjado fino, del Clásico terminal y Postclásico temprano.

Pedregal I. Se localiza en la ranchería del Pedregal que está ubicada sobre la margen izquierda del Caribe. Aparentemente la población actual se edificó sobre una zona habitacional prehispánica. Algunos tiestos no diagnósticos así lo indican.

Pedregal II. Este sitio se encuentra a la salida del poblado, como a unos 20 minutos, sobre el camino a El Zarzal, que dista unos minutos a caballo de Pedregal, aproximadamente 8 kilórnetros de mal camino. Se trata de una zona habitacional ubicada sobre una serie de elevaciones, los terrenos son comunales dedicados a la ganadería; hoy dia el paisaje está totalmente alterado aunque se conservan algunos úrboles de chicozapote, cedros y chacás. Cerca del asentamiento se encuentra una aguada y en general los terrenos que lo rodean son bastante bajos. 
Pedregal III. Siguiendo la vereda que viene desde Pedregal, se pasa por otro lomerío pequeño, en donde se puede apreciar claramente un grupo de plataformas distribuidas de tal manera que forman una plaza entre tres o cuatro estructuras, aunque existen otras. En el conjunto se encuentran algunos árboles de chicozapote, que conservan los cortes caracteristicos hechos por los chicleros sobre la corteza, ya que un gran número de personas se dedica o se dedicó a la explotación del chicle.

Hoy dia, los terrenos en donde se encuentra localizado este sitio estin destinados a la ganaderia exhaustiva, lo que ha repercutido sensiblemente en la alteración del paisaje.

El Zarzal. Este sitio, visitado como punto final del reconocimiento de esta parte, se alcanza después de dejar el camino principal y adentrándose hacia el noroeste por los potreros. Los terrenos en donde se encuentra son ejidales y dedicados a la ganadería. En esta época del año el camino es intransitable a pie y aún a caballo se dificulta bastante.

Destaca por su monumentalidad y tiene caracteristicas similares a Santa Clara. Se extiende aproximadamente por unas 50 has., aunque no recorrimos la totalidad del asentamiento. Sobresalen unas 20 estructuras, algunas de unos $15 \mathrm{mts}$, de altura, y grandes plataformas sobre las que existen basamentos $y$ altares. Asimismo pueden apreciarse plazas, basamentos piramidaies y posiblemente para sostener casas (Figura 7). Hacia ei sur, de ésta que podemos considerar la parte central de El Zarzal, se localiza una aguada y algunos grupos de edificios distribuidos en los alrededores, como uno localizado al suroeste que conforma una pequeña plaza rodeada por tres estructuras. No se pudo recuperar un buen número de tiestos, pero de los pocos encontrados parecen corresponder al Clísico, sin embargo, es probable que las ocupaciones tengan un rango cronológico del Clásico temprano al Postclásico temprano, por lo menos.

Como apuntamos, se trata de un asentamiento bastante importante, no soblo por las caracteristicas monumentales que presentan los edificios, sino porque se encuentran dentro de terrenos bastante productivos, de acuendo a la información que nos fue proporcionada, si bien hoy día aquí no se practica la agricultura. Aunque alejadó del rio, la distancia es relativamente corta, unos seis kilómetros hacia un lugar denominado "Cerro Pelón" del que sólo supimos que es una zona arqueológica importante localizada cerca del río sobre la margen ixquierda. Hoy día el paisaje se encuentra totaimente al. 
terado y, como en los casos anteriores, tan sólo se conservan algunos árboles aislados: chacá, cedro, chicozapote y ceiba, aunque en ciertas zonas se aprecian manchas de acahuales.

\section{Río San Pedro}

Este es un río más angosto que los anteriores, aunque aparentemente en ciertas épocas del año es navegable en cayuco hasta Guatemala. Recibe en su recorrido algunos afluentes, pero nosotros no pudimos ocuparnos de su exploración. Por otra parte, el medio es bastante similar al que se presenta en los ríos anteriores, tanto en la vegetación como en la fauna, sólo que fisiográficamente es distinto, ya que no presenta las amplias planicies pantanosas. Aquí como en el Candelaria, a diferencia del Caribe, también pudimos apreciar trazas de lo que es denominado "canales", mismos que se pueden seconcecer en la fotografia aẻrea. Durante nuestra estancia registramos los siguientes sitios:

Paso Madera. Sitio habitacional de cortas dimensiones enclavado sobre la margen izquierda del rio.

El Uinal. Se localiza casi enfrente del sitio anterior, sobre la margen derecha del rio, pero imposible de visitar por las condiciones del terreno, por lo tanto, soblo lo apuntamos como referencia. Se nos informó que consta de varios montículos. Asimismo, aparentemente podría llegarse a ể en automóvil en épocas de secas.

Laguna La Fangosa. Este sitio $s e$ desarrolló a orillas de la laguna del mismo nombre, que se comunica con el rio por medio de un riachuelo, navegable sólo en cayuco en esta época. Sin embargo, se puede llegar a él por carretera desde Monclova por la brecha que conduce a El Uinal, puesto que se localiza antes de pasar el río, a mano izquierda. Este sitio se distribuye por unas cinco hectáreas y se compone de unas 20 estructuras, algunas de $8 \mathrm{mts}$. de altura, aunque las más miden unos $3 \mathrm{mts}$ (figura 8 ). El terreno está dedicado a la ganadería por lo que el paisaje ha sido totalmente alterado a causa de la tala indiscriminada. En general los edificios están bien conservados y el sistema de construición es de piedra. Los edificios se distribuyen en grupos; uno cerca de la laguna y el otro un poco mís alejado, en éstos se puede ver espacios cerrados por 
la forma en que se dispusieron los edificios. En apariencia la cro nologia podría ser del periodo clásico.

San Romain. Reportado por W. Andrews en 1943, se encuentra sobre la margen irquierda del rio y sobre unas elevaciones de suave pendiente, El acceso es fundamentalmente fluvial, aunque se encuentra muy cerca del pueblo de Monclova. En la actualidad los terrenos están dedicados al cultivo de maíz Los montículos se en. cuentran distribuidos de manera dispersa en unas 10 has, o más. No se puede decir nada de su sistema de construcción, pero la principal ocupación cae hacia el Clásico terminal y Postclásico tempra. no, de acuerdo a la cerámica recuperada.

El Limón. Se localiza sobre la margen derecha del rio y sobre terrenos elevados dedicados a la ganadería. Se trata de un sitio con estructuras relativamente pequeñas fundamentalmente habitaciones, aunque existen basamentos que pudieron tener otra función. La cerámica apunta hacia el Clísico pero algunos tiestos caen hacia el Preclásico superior.

San Joset. Ubicado en ta margen izquierda del rio y casi frente al sitio anterior. Se trata de un conjunto de estructuras que posible. mente funcionaron como basamento de templos, entre las que des. tacan seis, distribuidos en unas dos hectáreas. EI saqueo ha sido continuo en este lugar que parece caer hacia el Clásico. Hoy dia el terreno está dedicado a la ganaderia, pero se pueden apreciar hua. nos, tintos, chacás, jobos y cedros.

Aun cuando se naveg6 rio arriba, no se localizaron sitios gran. des, si bien en algunos lugares aislados pudieron apreciarse restos de habitaciones en las partes altas de los terrenos elevados, lo mismo que trazas de los llamados "canales". Uno de ellos, muy claro como camino ya que conducia hacia un rancho.

\section{Sitios localizados hacia el Naranjo}

Fuera de la zona fluvial, se llevaron a efecto algunos recorridos por carretera. Uno de ellos se hizo entre Candelaria y un lugar denominado El Machetazo, en donde se nos informó existe un sitio muy grande. En ese reconocimiento se localizaron los siguientes si. tios: 
Paraiso Nuevo. Este sitio se encuentra antes de llegar a la estación del tren, sobre una parte alta, que posiblemente nunca se inunda y se podria clasificar como zona habitacional; al lado derecho de la carretera (brecha) poco después de pasar el rancho el Alazín.

El Naranjo. El sitio está ubicado muy cerca de la estación del fe. rrocarril y de la brecha; se trata de unos 7 monticulos habitacionales.

Los terrenos están dedicados a los pastizales para el ganado, existen además aigunos árboles como flambollanes y el palo de tinte. Los montículos se distribuyen aproximadamente por una hectárea.

La Rancheria. Ubicado en terrenos propiedad del Sr. Moisés L. pez, el sitio fue dividido por la terraceria (Figura 9). Los terrenos están dedicados fundamentalmente a pastizales, aunque existen al. grunos huanos y árbioles de diferente especie; muchos de ellos habian sido cortados hacía poco.

El asentamiento se encuentra en una loma que fue nivelada y aprovechada para hacer las construcciones; desgraciadamente el sitio ha sido muy saqueado; casi todos los montículos tienen profundos hoyos de saqueo (Límina XIII).

El sitio quedó dividido en dos partes por el camino que conduce al Machetazo, el grupo norte y el grupo sur. El primero es el que tiene mayor número de estructuras, aunque todas de dimensiones relativamente pequeñas. El grupo sur consta de tres grandes estruc. turas que pueden verse desde varios kilometros antes de llegar al sitio y sus alturas pueden ser mayores de $15 \mathrm{mts}$. Este lado no fue visitado por algunas dificultades en los reconocimientos; sin lugar a duda deben de existir muchas estructuras de menores dimensiones. que desde lejos no pueden ser vistas ni registradas.

$\mathrm{Ei}$ área en donde se distribuyen las 13 ó 14 estructuras ocupan aproximadamente unas 10 hectáreas.

Los pozos de saqueo, abundantes y profundos han dejado al descubierto el sistema de construcción que es de piedra cortada con un relieno del mismo material. La distribución de los edificios forman plazas y grandes conjuntos.

\section{Sitios localizados hacia la colonia Estado de México}

Para completar el reconocimiento que habiamos realizado por el río Candelaria y el río San Pedro, decidimos hacer un reconocimiento 
por carretera desde la población de Candelaria hacia donde se han ubicado una serie de colonias de reciente creación; la más antigua de hace unos 20 años: Estado de México, Monclova y Coahuila, entre otras.

Estado de México. Sobre el lado derecho de la carretera que va hacía la colonía Estado de México, y poco antes de la desviación que existe hacia la colonia Pablo García, pero dentro de terrenos del ejido Estado de México, encontramos este asentamiento que recibe el mismo nombre del ejida. Cuenta con un centro principal que puede verse desde la carretera, compuesto por grandes estructuras.

En cuanto a su distribución podemos decir que se ve un cierto orden en la disposición de los montículos principales que se ubican sobre una elevación natural, en donde se formó un pequeño centro compuesto por las principales estructuras. A este sitio no se nos permitió el acceso.

La Viuda. Se localiza entre las desviaciones hacia P. García y Estado de México; este sitio no se puede ver desde la carretera, sin embargo, por la información que se obtuvo, al parecer se trata de un sitio de cierta importancia, fue registrado únicamente por tratarse junto con el anterior de sitios tierra adentro, puesto que el acceso no es fácil.

Laguna El Perico. Como a cios kilómetros de la colonia Estado de México sobre la carretera y frente a la laguna, el sitio es visible desde la carretera y está dentro de los terrenos del ejido.

Este sitio al parecer está formado por plataiormas dispersas y se trata, seguramente, de un sitio habitacional, aunque existe la posibilidad de que el centro principal se localice frente a la laguna; por el escaso tiempo y carecer de un perniso de las autoridades municipales y ejidales, nos conformamos con el registro de lo que se veía desde la carretera.

Se trata de montículos muy bajos; no tienen más de uno o dos metros de altura. El sitio se extiende aproximadamente por unos tres kilómetros, frente a la laguna.

Monclova. El acceso a este lugar se encuentra un kilómetro antes de llegar a la población del ejido de Monclova, a orillas de la carretera, y se trata con toda seguridad de un sitio habitacional, pues ninguno de los montículos observados sobrepasa los dos metros de altura como máximo. 
Posiblemente el asentamiento se distribuya a lo largo de un kilómetro, tampoco pudo hacerse una visita minuciosa del sitio por las razones antes mencionadas, Lo registramos con la intención de que aparezca en el mapa. Los terrenos están dedicados a la agricultura.

\section{Sitios hacia Miguel Alemán}

Con este recorrido pretendiamos cubrir la otra orilla del río Candelaria por tierra. Nos habiamos propuesto salir de la población de Candelaria, rumbo a Pejelagarto, para de ahi seguir a la colonia Miguel Alemán y después al Chilar, que se localiza frente al Tigre, con el objeto de obtener la mayor información posible sobre sitios arqueológicos.

Debido fundamentalmente a las condiciones del camino que, para esa época todavia se encontraba en bastante mal estado, fue casi imposible el recorrido; con dificultades llegamos a Pejelagarto, sin alcanzar la población de Miguel Alemán porque el camino era intransitable, por lo tanto informaremos solamente nuestro recorrido, hasta donde llegamos, tratíndose fundamentalmente de sitios arqueológicos habitacionales $\mathrm{y}$ de alguno con otras caracteristicas.

Empezaremos la descripción de los sitios vistos entre Candelaria y Pejelagarto; posteriormente de Pejelagarto al sitio denominado por nosotros como La Poza, que fue hasta donde llegamos, el cual está localizado dentro del ejido Pejelagarto en los limites con el de Miguel Alemán.

Pejelagarto. Existen dos pequeñas zonas habitacionales, que por las condiciones del terreno no fueron visitadas. Se registraron desde el camino que va hacia Pejelagarto. Son montículos que no sobrepasan los dos metros de altura asentados en la parte alta de algunas lomas.

Cuyo Partido. Se trata de un pequeîo grupo de plataformas que se localizan hacia Miguel Alemán. El montículo principal fue cortado por la brecha, y se nos informó que salieron varias vasijas cuando se destruý el montícula.

Se hizo un sencillo croquis en donde se registra la orientación de los montículos y la ubicación de los mismos con respecto a la brecha.

Las Pozas. Se encuentra enclavado en el lado derecho de la brecha del camino que va hacia Miguel Alemán, dentro de los terrenos 
del ejido Pejelagarto. Cuenta con un centro principal en donde se concentran los montículos más grandes en una extensión que sobrepasa las 15 has,, incluye los principales monticulos (Figura 10).

Este es un sitio monumental con estructuras grandes y con distribuciones muy especiales, además los montículos están separados por distancias de aproximadamente 400 a 500 metros. La plataforma principal que visitamos tiene un frente de 200 metros de largo y sobre la parte superior tres montículos con una altura de unos 10 mts. (Lámina XIV).

De este sitio solamente hicimos el croquis de la plataforma y la localización de los montículos principales, tomando las distancias aproximadas y las orientaciones.

Es posiblemente uno de los sitios más sobresalientes que visitamos fuera de las márgenes del río Candelaria, en cuanto a las dimensiones de las estructuras.

En Pejelagarto visitamos a un cazador que al parecer conoce muy bien la región por quien supimos existe un buen número de sitios arqueológicos.

Resumiendo, la información que nos dio el Sr. Emilio Pacheco Balám en Pejelagarto, se puede sintetizar de la siguiente manera: 1.-Cerca del río de Pejelagarto en el Rancho de los Soler, existe un sitio grande.

2.-Entre Pejelagarto y Miguel Alemán hay otros sitios.

3.-Rumbo hacia El Chilar se localizan los siguientes sitios:

- Rancho,

- Canules,

- Ruinas,

- Pocito.

4.- Habla de otros sitios cerca de Pejelagarto y de Miguel Alemán.

El objetivo de nuestras averiguaciones se refiere fundamental. mente cerca del rio Candelaria y no tierra dentro, aunque es interesante señalar la existencia de sitios importantes hacia el interior. Con esta información pensamos que tenemos un primer acercamiento a la arqueología del Candelaria, que solamente era conocida a través de los trabajos publicados por Andrews en 1943.

\section{Resumen $y$ apreciaciones generales}

En páginas anteriores hemos hecho una descripción general de los sitios arqueológicos visitados durante el reconocimiento llevado 
a cabo en 1983. La duración de los trabajos fue de tres semanas efectivas de campo, pero las condiciones climáticas de la época impidieron que éste fuera más detallado. De todas formas, nos interesa dar a conocer lo registrado en tanto que poco es lo que se había hecho en este aspecto en la cuenca ( $C$ fr. Andrews, 1943). Por razones estratégicas en algunos casos tuvimos que adentrarnos de las orillas del río, con el propósito de obtener un panorama más completo de la distribución de los asentamientos en el área. De varios sitios la información es incompleta, pero nos parece que servirá de punto de referencia para futuras investigaciones.

Las causas que nos llevaron a este primer acercamiento a la arqueología de la cuenca del Candelaria se justifica por varias razones: en primer lugar, por falta de noticias después de lo publicado en 1943. En segundo término, consideramos necesario obtener información directa relativa a la existencia de campos en donde supuestamente se practicaba la agricultura de manera intensiva pot medio de camellones, así como la presencia de canales utilizados con Este $y$ otros propósitos. En tercer lugar, nos interesaba recabar ciertos datos relativos a las rutas de comunicación y de comercio, la forma en que podrian haber funcionado a lo largo de las cuencas que recorrimos, anotando las posibilidades que ofrece el medio para el efocto, en relación a los asentamientos y la localización de puntos de embarque $y$, cuarto, porque esta investigación sería factible de complementarse con el estudio de las fuentes históricas. Con toda esa información pensamos que en un futuro, con trabajos complementarios, estariamos en condiciones de dar una interpretación preliminar sobre los procesos de desarrollo ahí ocurridos. Este pues, no pretende rebasar los propósitos de un informe general sobre las ocu. paciones de la cuenca del Candelaria.

Como se ha apuntado, el paisaje actual no es, ni por asomo, parecido al que debió reinar durante la época prehispínica y hasta hace relativamente poco tiempo, $\mathrm{La}$ introducción de la ganadería y la apertura de nuevas colonias de población en el área han conformado una zona de transición entre las sabanas y la selva tropical, con un absoluto predominio de las primeras, que han acelerado la alteración del medio. Los ríos, sin embargo, continúan siendo el medio más apropiado para la obtención de alimentos, a la vez que constituyen la via de comunicación más expedita. Pero aún esto último habrá de terminar en corto tiempo dado el acelerado ritmo con que se estín abriendo caminos por tierra, asunto que si bien parece secundario para las investigaciones arqueológicas, en verdad 
es relevante, toda vez que la gran mayoria de sitios se encuentran cerca de las cuencas y las áreas de mantenimiento de las poblaciones prehispánicas que funcionaron en relación a éstas.

Aunque procuramos anotar las características del paisaje, salve algunos casos en los que se conservan restos de la flora y fauna nativas, en términos generales éstas prácticamente han desaparecido. A pesar de ello, sabemos que antes predominaba la selva alta en esta área, pero, en todo caso, nuestro punto de referencia lo constituye las características de las cuencas que visitamos: Candelaria, Caribe y San Pedro. La primera, aunque poco estudiada, viene a ser la corriente más importante del estado de Campeche y, en la época prehispánica y hasta hace unos cuantos decenios fue, junto con el Usumacinta y Grijalva, una de las vías más utilizadas en la comunicación y el comercio entre la costa y tierradentro, aun cuando en apariencia fue olvidada por los viajeros del sigio xix y principios de éste. Por lo menos, no encontramos hasta ahora ninguna referencia sobre el particular.

En la cuenca predomina el clima tropical con intensas lluvias de verano (Aw), propio de las regiones de selva tropical. En ciertas zonas cercanas a las orillas de los rios predominan los tintales, el zapote de agua o zapote bobo, el guirro, chacá y la vegetación de matorral; pero, sin duda alguna, la vegetación más importante la constituyen los juncos y espadañas que en otro tiempo $y$ hoy dia en ciertos lugares se aprovecha para la manufactura de petates, canastas y cestos. Un poco más retirado de las orillas y en el interior, chacá, ramón, cedra caoba, jobo, jabin, maculi, chicozapote y pucté, entre otros, todavia pueden encontrarse, sin que falten palmeras de guano, coyol y palma redonda. Asimismo, abundarot ahi los venados, tigres, tigrillos, jabalies, mico de noche, puerco espin y oso hormiguero, sin olvidar que aves como la chachalaca, el pavo de monte, perdiz, tucán, aguililla, loros y diversas aves acuáticas como patos y garzas es posible encontrarlas de vez en vez. Los ríos y lagunas todavia albergan una amplia variedad de tortugas y peces, sin que en todas partes falten las viboras de cascabel, nauyacas y coralillos (Lámina XV). Los peces se "almacenan" en trampas especiales (viveros), con el propósito de venderlos frescos o consumirlos cuando se van necesitando (Lámina XVI).

En ese paisaje observamos que mientras la margen izquierda del Candelaria está conformada por suaves colinas, de origen calizo, aptas para albergar importantes núcleos de población, la margen derecha, en cambio, está conformada por una amplia planicie que 
permanece inundada gran parte del año, sin posibilidades de ofrecer alternativas para los asentamientos. Sin embargo, ha sido sobre esta margen en donde se han detectado los supuestos camellones destinados a la práctica de la agricultura intensiva, sin que falten sobre la margen izquierda. Esta misma conformación natural existe hacia el Caribe, pero no para el San Pedro que, como en su oportunidad indicamos, tiene caracteristicas fisiográficas diferentes; más aún, sobre este rio, aunque existen canales y acaso también camellones, los asentamientos se encuentran indistintamente sobre una u otra margen del río. Por esta similitud entre el Caribe y el Candelaria y la forma en que se unen en la Boca de Santa Isabel, da la impresión de que en realidad el segundo es continuación del primero y que, si bien se torna un poco más caudaloso ello es resultado de que en ese punto se alimenta con las aguas del San Pedro que claramente es una corriente diferente.

Corno se ha indicado, nos tocó visitar varios asentamientos tanto sobre las márgenes de las cuencas como otros localizados un poco más al interior. Los asentamientos se caracterizan por ser en unos casos únicamente habitacionales, con extensiones variables, pero pot lo regular menores de diez hectáreas. En otros, se trata de zonas habitacionales con pequeñas plataformas para sostener templos o casas de personas importantes, aunque no es dado hablar de centros políticos-religiosos formales; en todo caso también se trata de asentamientos de corta extensión aunque no menores de diez o quince hectáreas. Finalmente, podemos hacer referencia a los asentamientos que poseen claramente un núcleo politico-religioso, rodeado por una extensa área habitacional dentro de la cual, con frecuencia, se aprecian conjuntos menores formados por plataformas arregladas alrededor de plazas, $\mathrm{y}$ aunque es factible distinguir estos conjuntos, en un reconocimiento de superficie es dificil saber si son contemporáneos o no. En ciertos lugares se han distinguido posibles áreas de actividades, zonas de explotación de recursos naturales y abrigos que bien pudieron funcionar como puntos de embarque o puertos. En su mayor parte los sitios rebasan las cincuenta hectáreas de extensión y en uno de ellos es posible que sobrepase los cinco kilómetros cuadrados. Edificios monumentales de más de veinticinco metros de altura, calzadas, juegos de pelota y estructuras de casas importantes son frecuentes. Por lo regular estos sitios ribereños se encuentran localizados en puntos claves para el control de la navegación y el comercio: Salto Grande, El Tigre, Santa Clara y Cerro de los Muertos principalmente, En determinados lugares fue factible 
detectar la presencia de camellones, esas anomalias en el terreno que han sido tomadas como campos destinados a la práctica de la agricultura intensiva, asi como otras formaciones singulares que se han interpretado como canales.

En estos últimos aspectos, llama la atención que en las fuentes no aparezcan referencias sobre el particular, excepto en el caso de los canales que Thompson interpretó como la creación de un nicho ecológico artificial con base en los Papeles de Pablo Paxbolon Mal. donado (1974). Sin embargo, el canal al cual se refirió dicho autor, que hoy dia conduce al ejido de El Chilar (Lámina XVII), aparentemente fue abierto en el siglo pasado, como es probable que hubieran sido abiertos muchos de los que han sido interpretados como tales (Millet, 1984), con el propósito de extraer productos forestales, pues por medio de éstos se facilitaba su transporte hacia los ríos para poder conducirlos hacia el mar, asunto que no es ex. clusivo de esta área, pues para la Huaxteca se hicieron obras similares. En cuanto a los camellones, no deja de ser curioso lo que apuntamos en su oportunidad, que éstos permanecen bajo el agua un lapso bastante considerable y se haria necesario investigar si en ellos se practicaba el cultivo de productos de cielo corto o bien resistentes a la humedad (Láminas XVIII y XIX). De todas formas, con nuestros trabajos hemos averiguado que la mayor parte de esos supuestos canales, son en realidad "caminos" abiertos en los bajos y no obras excavadas (Láminas IV, XVII y XX). En efecto, hoy día los campesinos para llegar a sus milpas o a sus ranchos, acortan las distancias por medio de éstos ahorrándose las grandes vueltas que da el río; para ello retiran la vegetación acuática y abren un claro por donde solamente pasa el cayuco (Límina XX). Este paso puede permanecer abierto durante algún tiempo, pero si se abandona se va cerrando quedando sólo la huella del mismo (Lámina XVII); de tal manera que con frecuencia pueden abrirse varios de estos pasos unos muy cerca de otros dando la impresión de una red inmensa de canales. Con ello, por supuesto, no estamos negando que no hubieran existido verdaderos canales en la época prehispánica, pero en esta zona su funcionamiento en relación a la agricultura es bastante dudoso, toda vez que no tienen posibilidad de meter o sacar agua por las condiciones del terreno. Sin embargo, no es remoto que en la época prehispinica se hubieran abierto estos "caminos acuáticos" con el mismo propósito que en la actualidad.

Todo lo anterior nos ha llevado a sustentar, como en otras ocasinnes lo hemos hecho con otras bases (Ochoa, 1979), que sin negar 
que los antiguos mayas conocieran y manejaran métodos para la agricultura intensiva de carácter hidráulico, sostenemos que las superficies eran relativamente reducidas y restriugidas a las áreas inmediatas o muy cercanas a los grandes centros. En tanto, villas, aldeas y pueblos se mantuvieron por medio de la práctica de la agricultura extensiva, lo que nos ha llevado a considerar que en las tierras bajas del área maya coexistieron dos formas de agricultura, una intensiva controlada y usufructuada por la élite y otra extensiva practicada por el resto de la población que, independientemente, debe de haber pagado con trabajo el mantenimiento y explotación de los campos cultivados de manera intensiva (Ochoa, $o p$, cit.).

Asimismo, el comercio en esta área jugó un papel sobresaliente en la economia de las Tierras Bajas Noroccidentales, a tal grado que en algunas provincias que no contaban con tierras suficientes para la práctica de la agricultura, fue éste la base de su desarrollo (Cfr. Vargas y Ochoa, 1982). Creemos que se hace necesario revisar estos puntos, ya que el conocimiento del papel jugado por la combinación de la práctica intensiva y extensiva de la agricultura, el comercio y la explotación de los recursos naturales, podria ayudarnos a explicar con mayor claridad las bases del desarrollo de esta cul. tura. Desde nuestro punto de vista, la teoria hidráulica ha sido llevada más allá de los datos confiables. Es necesario reconsiderar otros aspectos que no han sido tomados en cuenta en conjunto, con el propósito de obtener una visión más aproximada a la realidad.

Finalmente, ya hemos anotado nuestras consideraciones en cuanto a la cronología de algunos sitios, solamente nos resta subrayar que la cuenca estuvo ocupada desde, por lo menos, el Preclásico superior hasta el momento del contacto. Cerámica diagnóstica: Sierra rojo, Tinaja, Gris fino, Anaranjado fino, Plano relieve y Matillas, entre otros, dan buena cuenta de esto (Figuras 11 y 14). Algunos sitios claramente estuvieron habitados durante el último momento y contacto, pero con los elementos de juicio con que contamos, todavia es imposible identificar con absoluta certeza algunos de ellos con los registrados en las fuentes. Tal seria el caso de El Tigre, que como apuntaran Scholes y Roys primero, y después Piña Chán y Pavón Abreu, tal vez pudiera corresponder al lugar más importante de la provincia de Acalín: Itzamkanac. En efecto, no obstante su arquitectura monumental, cronologia, enclave estraté gico como punto de control del tráfico con su puerto natural y las descripciones de Hernán Cortés, acordes en gran medida con lo que es dado apreciar en el campo, no se puede aseverar sin las de- 
bidas reservas tal identificación. Sin embargo, tampoco es posible negar que se trata de un lugar de primera importancia que ofrece todas las condiciones para haber sido un puerto de gran tráfico comercial. Ahora bien, las referencias a detalles como el camino (¿ calzada?) que cruzaron para llegar a Itzamkanac el conquistador y Paxbolonacha, aunque existe, no ha sido fechado, aun cuando el mismo Cortés dejó escrito en su Quinta Carta, que aquél le rogaba:

(Se) fuese al pueblo principal donde él residía, porque alli había más parejo de darme las cosas necesarias y luego mand 6 abrir un camino muy ancho para allá, y él se quedó conmigo, y otro dia nos partimos, y le mandé dar un caballo de los míos, y fue muy contento cabalgando en él hasta que liegamos al pueblo que se llama Izancanac, el cual es muy grande $y$ de muchas mezquitas, y está en la ribera de un gran estero que atraviesa hasta el puerto de Términos de Xicalango y Tabasco.

AGRADECIMIENTOS: la realización de este trabajo no hubiera sido posible sin el apoyo y ayuda de varias personas $\mathrm{e}$ instituciones. De todas ellas quisiéramos destacar la valiosa asistencia del señor Julián Soler, tal vez uno de los mejores conocedores de la cuenca del río Candelaria y sus afluentes. El se encargó de conducirnos a prácticamente todos los sitios arqueológicos y poblados localizados en esa parte de la zona; él mismo nos introdujo con muchas personas en cuyos terrenos se localizan los asentamientos. De la misma manera nos asistió identificando junto con nosotros, cada meandro del Candelaria, Caribe y San Pedro, y las distintas particularidades que podiamos apreciar en la fotografía aérea y, más aún, nos brindó la hospitalidad de su casa en donde siempre fuimos bien recibidos por su esposa Blanca. De manera complementaria, el Cap. piloto aviador Plinio Valenzuela, de Emiliano Zapata, Tabasco, nos ayudó desde el aire en el reconocimiento de algunos sitios arqueológicos, "canales" y camellones en los sobrevuelos que realizamos sobre la cuenca. De invaluable valor fue la calurosa acogida con que nos recibieron los habitantes, autoridades municipales y ejidales de EI Tigre y EI Pedregal; sin olvidar la ayuda de los dueños de ranchos y ejidatarios de la zona en donde trabajamos. Personas de Candelaria como don Victor $\mathrm{X} \dot{e}$ y don Enrique Martínez se interesaron en nuestro trabajo y nos proporcionaron algunos datos sobre lugares que deberiamos visitar. Finalmente queremos dejar constancia de la ayuda de don Carlos Ontiveros, quien dibujó el mapa con la localización de los sitios reconocidos; Eladio Terreros pasó en limpio todos los croquis y Sofia Pincemin se encargó de dibujar algunos 
de los materiales cerámicos que aquf presentamos. Este trabajo, sin embargo, sólo pudo realizarse gracias al permiso concedido por el H. Consejo de Arqueologia del I.N.A.H. a los que suscriben a través del Centro de Estudios Mayas, institución que brindó el apoyo económico para llevar a cabo la investigación; los gastos de Sofia Pincemin fueron sufragados por el "Centre D'etudes Mexicaines et Centroamericaines" de la embajada de Francia en México. La última revisión de este informe fue mecanografiada por la Sra. Mag. dalena Corominas. A todos damos las más encarecidas gracias.

\section{BIBLIOGRAFIA}

Aonss, Ricrake E. W, W. E. Bnown y P. T. Culneat

1981 "Radar Mapping, Archaeology, and Ancient Maya Land Use", en Science, vol. 213: 1457-1463.

Annerws, E. Writys V.

1943 The Archasology of Southwertern Campeche, Carnegic Institution of Washington, Pub, 546, Wahhington, D.C.

Assullas, Peswo

1971 "Gardens on swaps", en Science, vol. 174: 633-661.

Contík, Hranin

1969 Cartas de Relación, Col. "Sepan Cuántos...", Nüm. 7, Ed. Porrúa, México.

Fennfíndez de Ovimo, Gonzalo

1959 Historia General y Natural de Indiar, Biblioteca de Autores Españoles, vol. III, edición y estudio preliminar de Juan Ptrez Tudela Bueso, Ediciones Atlas, Madrid.

Jimínez Vhloez, Glosia M.

1984 "Informe preliminar sobre el sitio arqueológico de Allende, Tabasco", en Esfudios de Cultura Maya, vol. XV; 55-75, UNAM, México.

Marcus, Joyce

1983 "Lowland Maya Archaeology at the Crossroads", en American Antiquity, vol. $48(3): 454-588$.

Mriset Címana, Lurs

1984 "Logwood and Archacology in Campeche", en Journal Anth. repologiral Reirareh, vol. $40(2)=324-328$, The University of

OchoA, LoRENzo New Mexico Press, Albuquerque.

1979 "Agricultura tradicional y agricultura hidráulica. Una dicotomia en el desarrollo y colapso de los mayas", en Jornadas de Historia de Occidente (Memoria), p. 7-11; Centro de Estudion de la Revolución "Láraro Clírdenas", A. C., Jiquilpan, Michoscán.

Ochon, Lonenzo y Banesto Vhrons

s/f "La importancia del estudio de las rutas de comunicación en la arqueologia de superficie" en Boletin del Centro de Entudios de la Reoolueión "Ldxaro Cárdenas", A. C., Jiquilpan, Michoacin (en prensa). 
1979 "Bl colapso maya, los chontalet y Xicalango", en Ertudios de Cultura Maga, Vol. XII: 61-91, Centro de Estudios Ma. yas, UNAM, México.

Pasa Cran y R. R. Pavós Anaze

1959 "¿Fueron las ruinas de El Tigre Itzamkane?", en Et Mixico

Ruz Latuncink, Ataritro Antiguo, tomo IX: 473-481, Mexico.

1969 La costa de Campeche en lor tiempos prehispánicos, Serie Investigaciones, núm. 18 , INAH, México.

Skotes, F, V. y R. L. Roys

1968 The Maya Chonial Indians of Acalan-Tixchel, a Contribution to the Hittory and Ethnography of The Yucatin Peninula, Carnegie Institution of Washington, Pub. 568, Washington, D.C.

Stzeress, Alrken y Dessis Peteston

1972 "Ridge Fields and Associated Features y Southern Campeche: New Perspectives in the Maya Lowlands", en American Antiquily. vol. $37(2): 229-239$.

Thoserson, J. Ensc S.

1974 "Canals of the Rio Candelaria Basin, Campeche, Mexico", en Mesoamerican Arehaeology: New Approaches, pp. 297-302, Norman Hammond ed., University of Texas Press, Austin.

Tuneze II, B. L. y Peran D. Hanusson (eds.)

1983 Pulltrowser Stwamp: Ancient Maya habitat Agricultural and settlement in Nortern Belize, Univenity of Texas Press, Austin.

Varons, Eenzsto y Lorenzo Ochon

1982 "Navegantes, viajeros $y$ mercaderes: notas pan el estudio de Ia historia de las rutas fluviales y terrestres entre la costa de Tabasco-Campeche y tierra adentro", en Estudios de Cultura Maya, vol, XIV; 59-119, UNAM, México. 



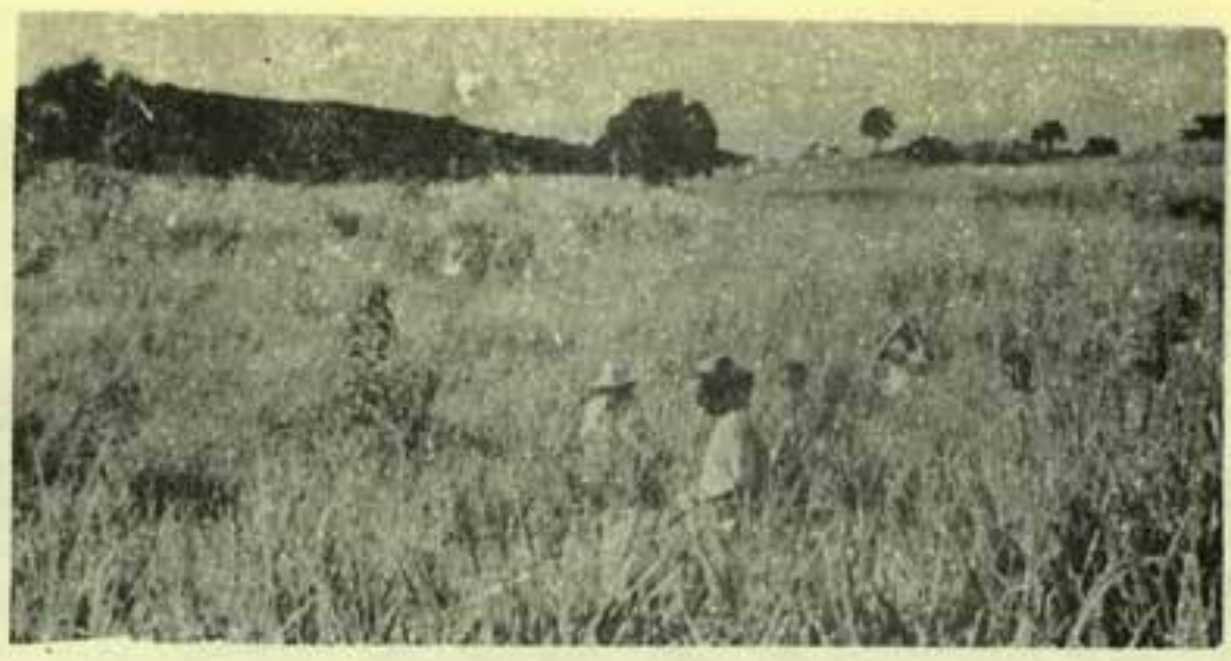

Lámina 1. Reconocimiento en la sona habitacional de Et Tigre durante el mes de noviembre.

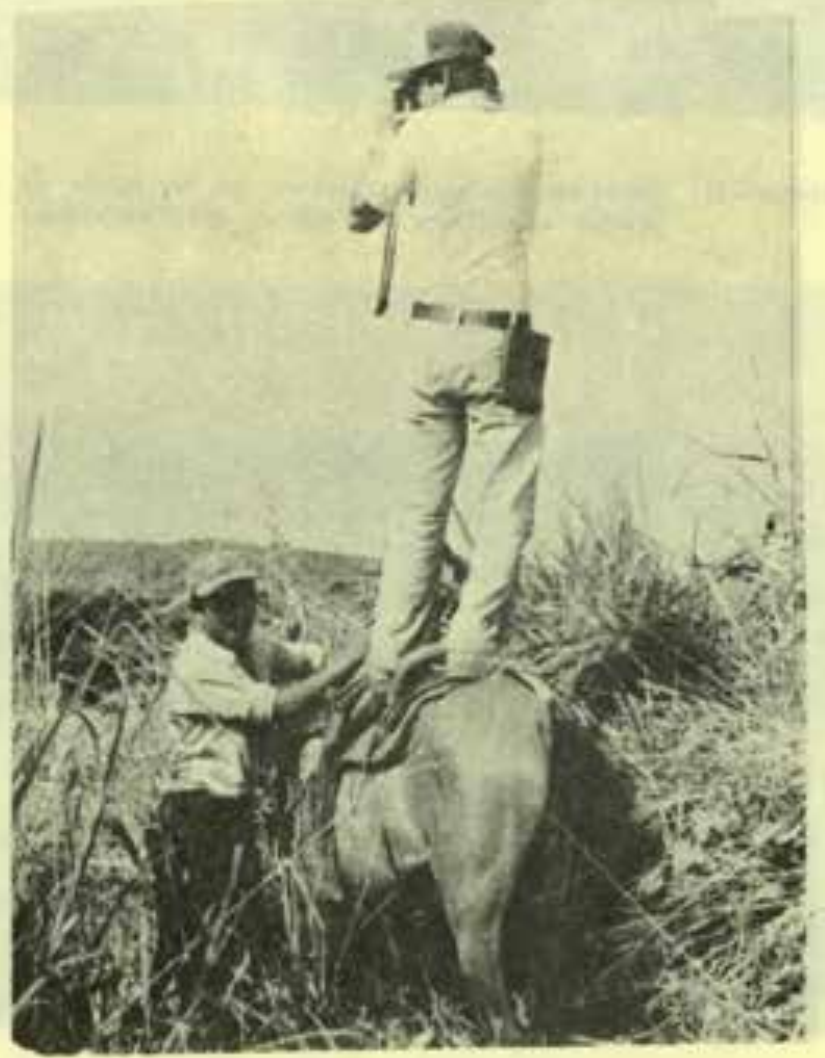

Limina II. Londiciones ambiestales que se presentan oespies de la rpoca de llevias en una mona dedicada a la príctica de la ganadería extensivu en la cuenca de Capdelaria. 


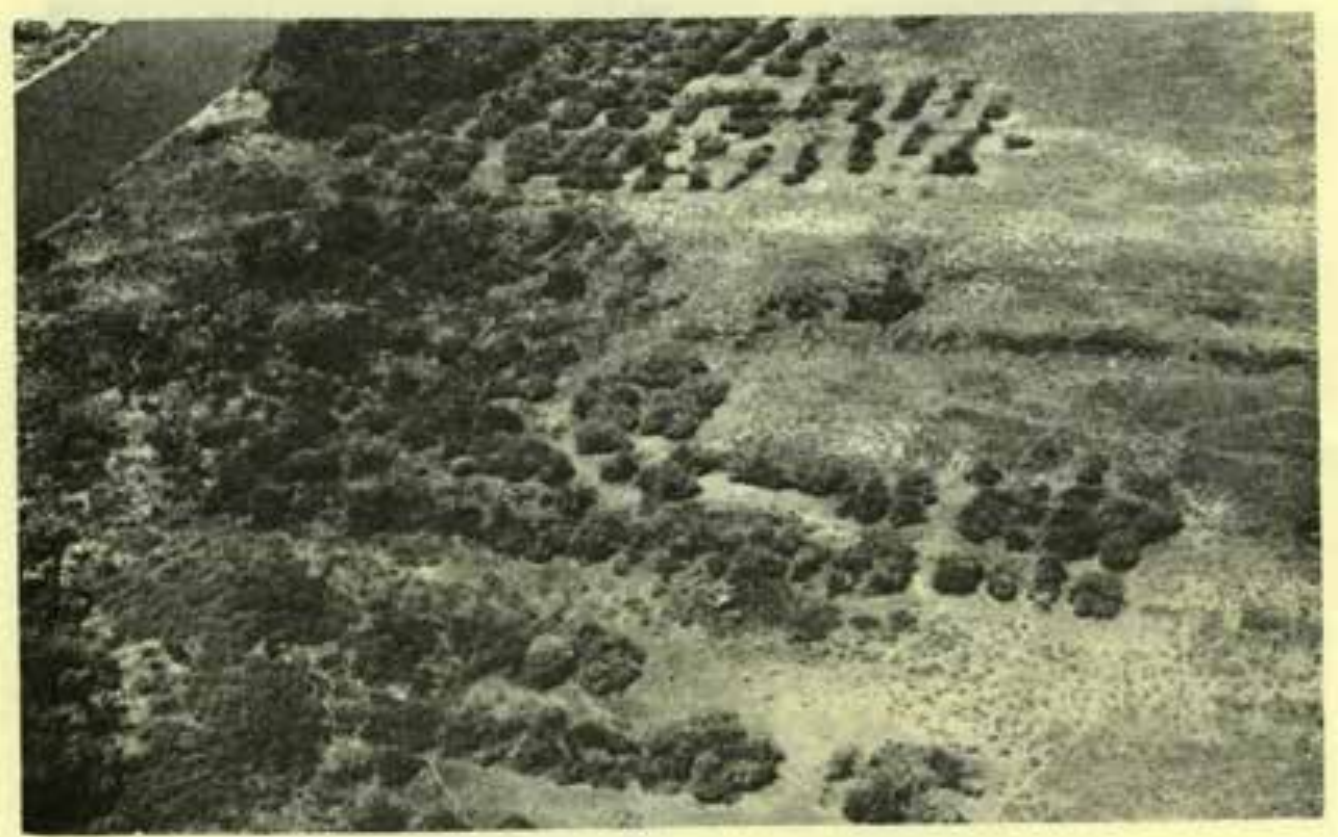

Límina III. Cancteristicas que presentan en la, época de secas los su- puestos camellones de cultivo del Candelaria.

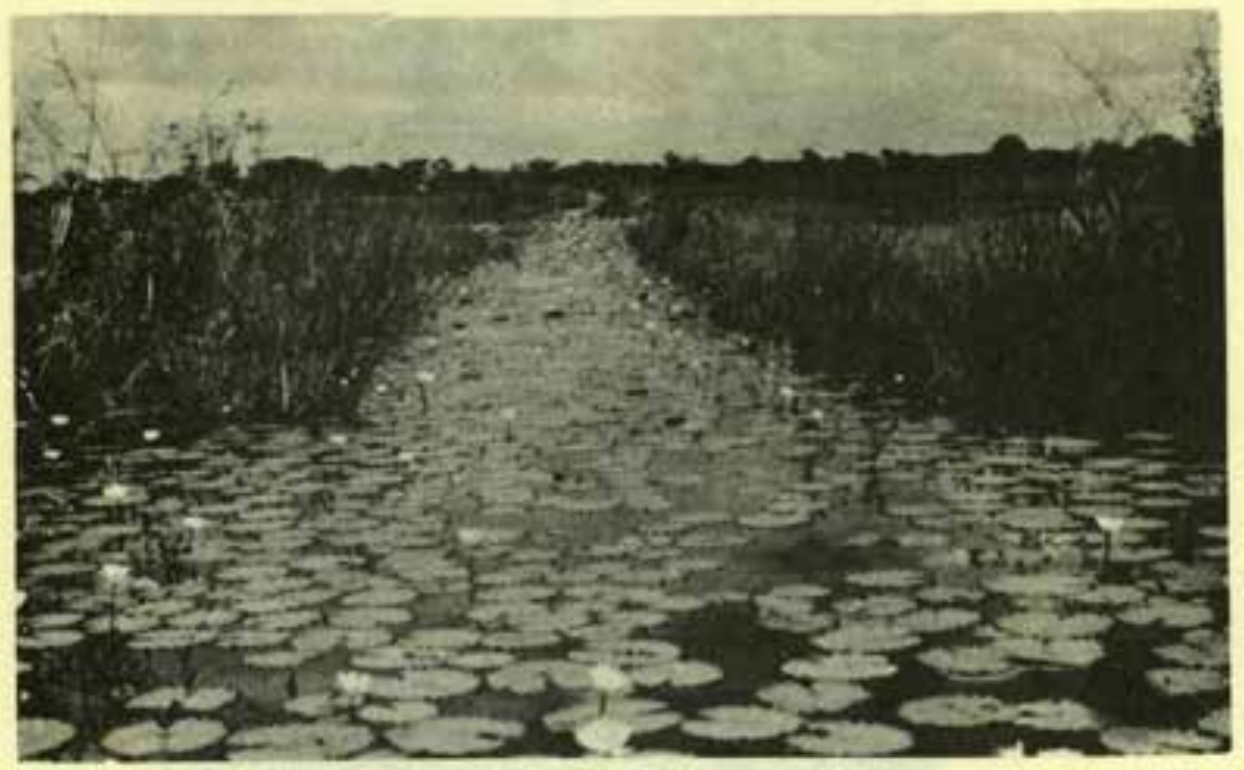

Lámina IV, Vista de un canal desde el río Candelaria después de la época de lluvias. 


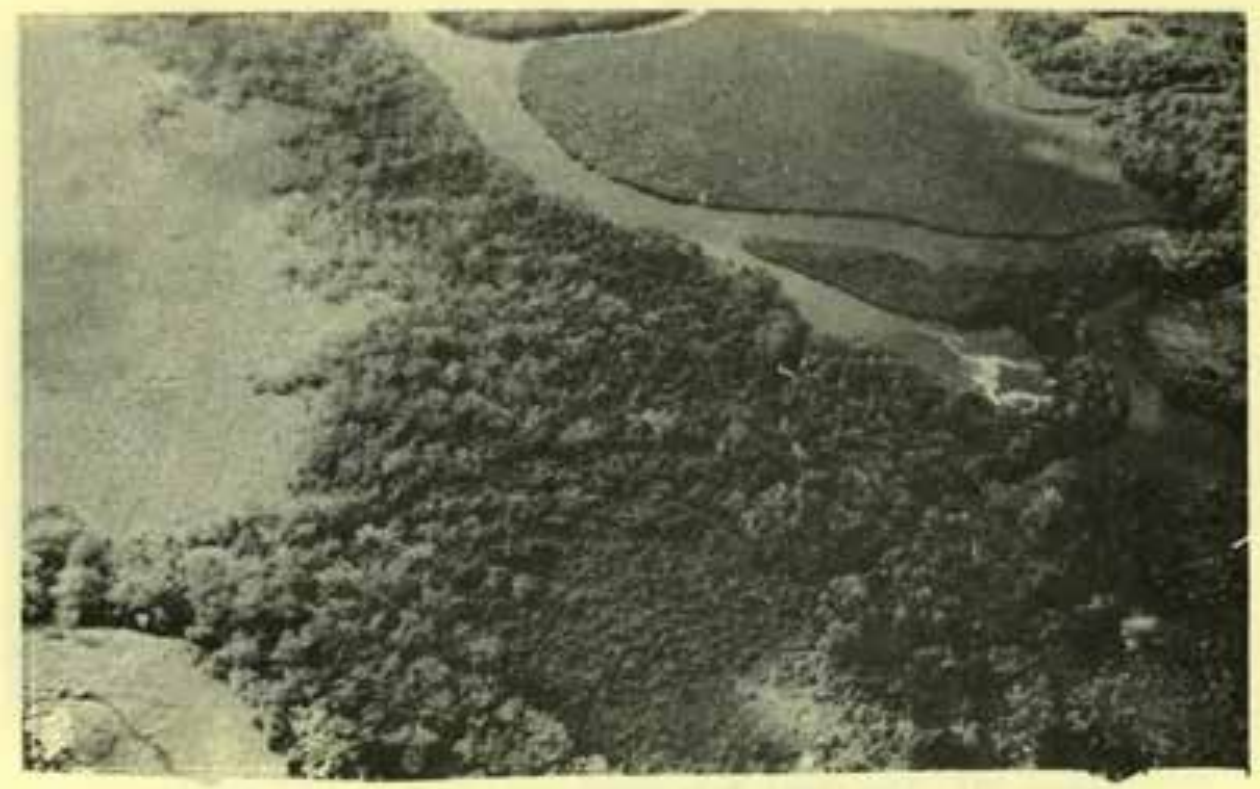

Lámina V. - Vusta aerea de los rapados cenocidos como "Salto Grande"; punto estratécico para el control del tráfico comercial.

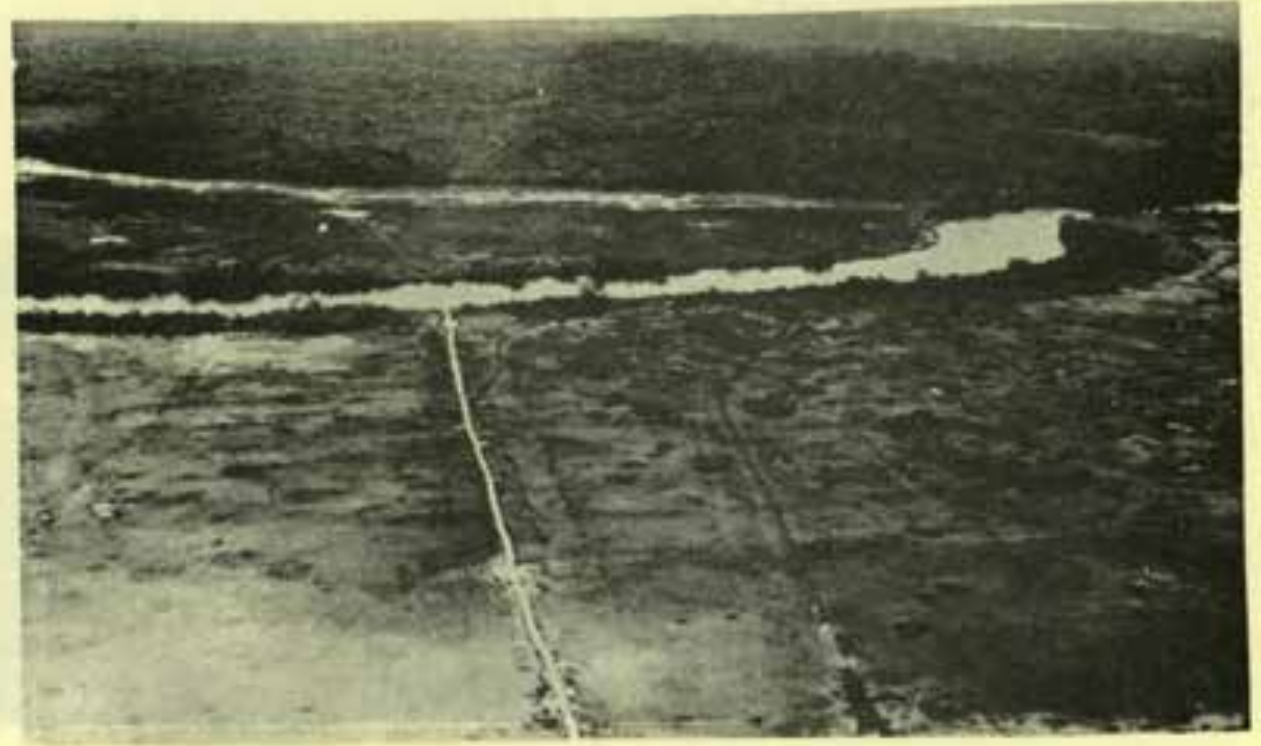

Lámina V1. Aspecto del paisaje desputs de la epoca de Huvas; esto dificulta el acceso a los sitios localizados en terrenos bajos. En el primer plano de la fotografia se aprecia un canal moderno y lineas diversas que corresponden a senderos hechos por va. queros o abiertos para navegar en cavocos. 


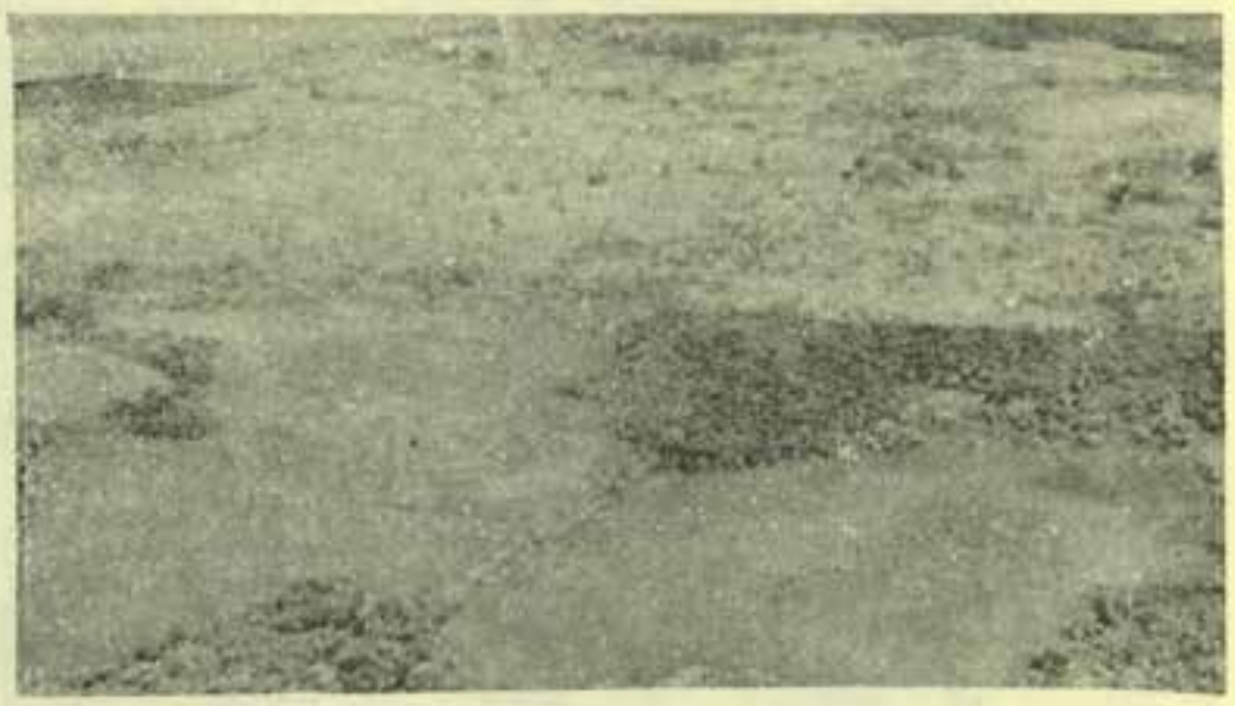

Lámina VII. Vista aérea de la calzada que une a los sition Pablo Garcia 5. Ei rigre a través de los pantanos.

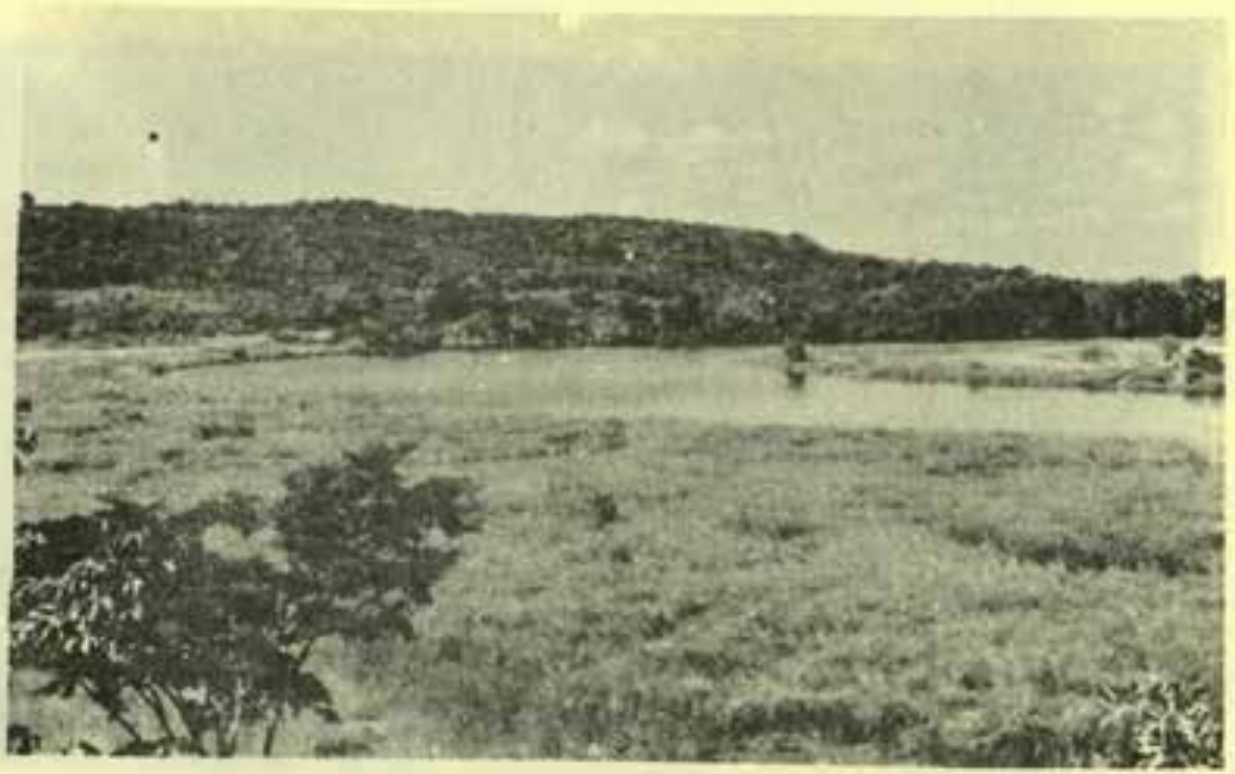

Lilmina VIII. EI Candelaria desde la ensenada que rerva de acceso a la calzada $\mathbf{v}$ al puerto de El Tiere. 


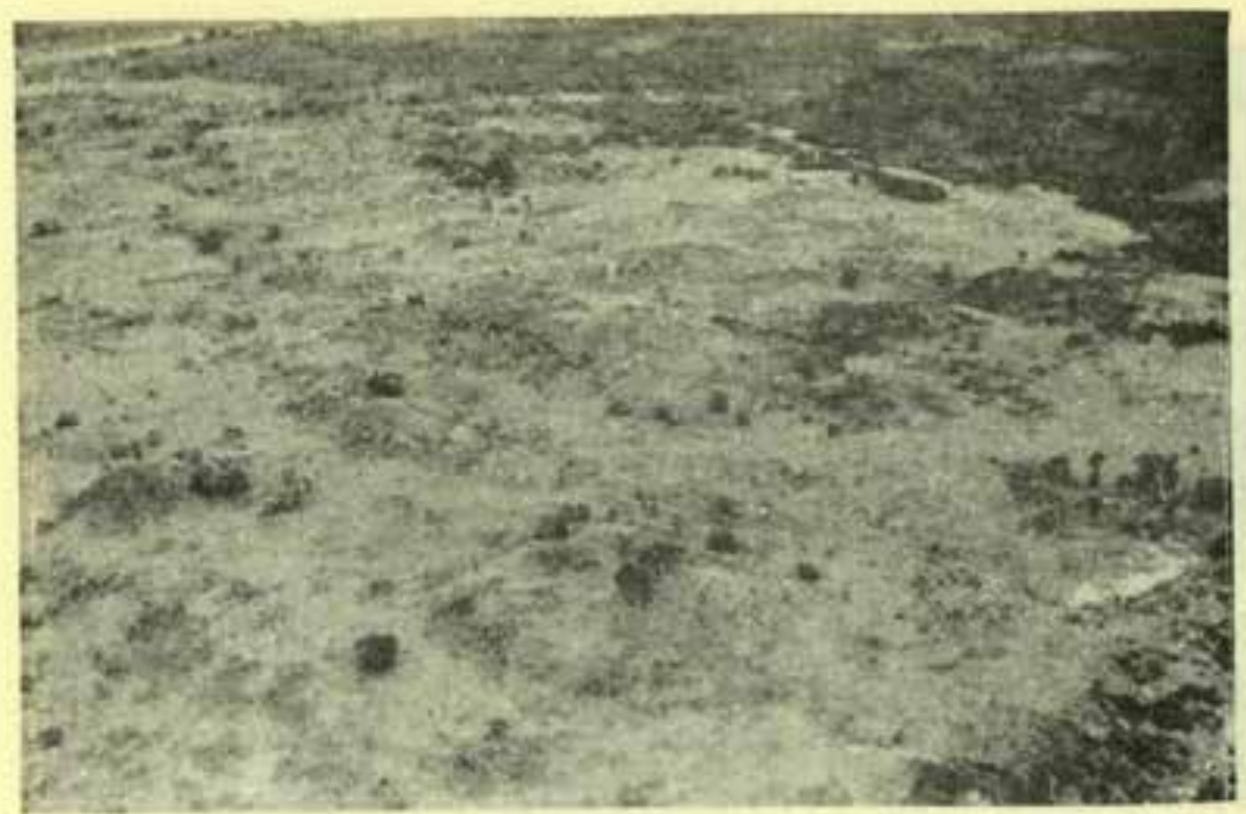

Lamina IX. Pancramaca de la zona central de til ligre después de la Éncea de tluvias.

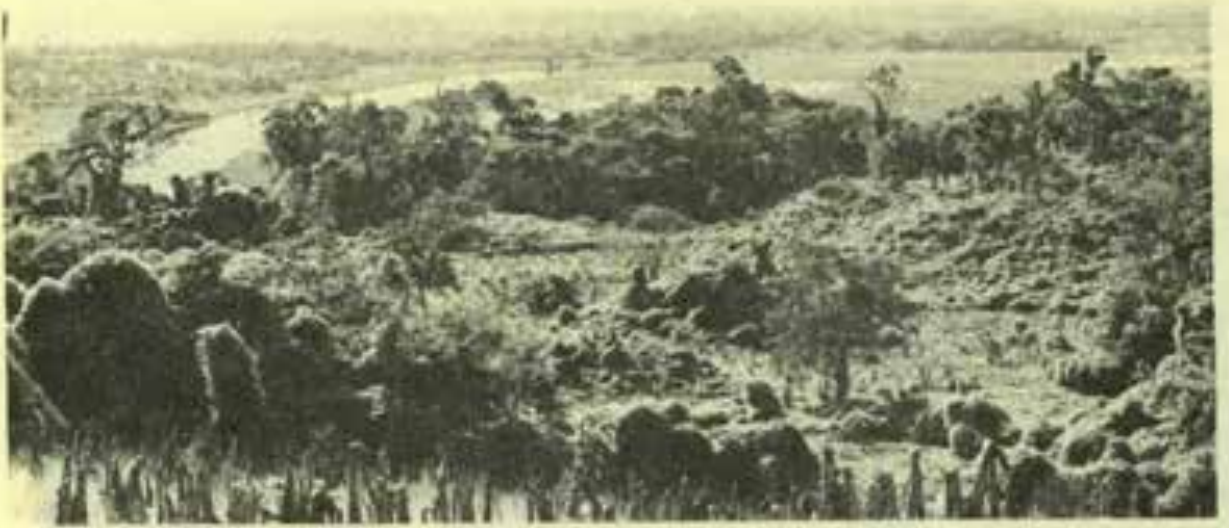

Lamina $X$. En el prumer plano uno de los conjuntos del Cerro de lus Muertos. Al fondo se aprecia la woma de terrencia bajos del Caribe. 


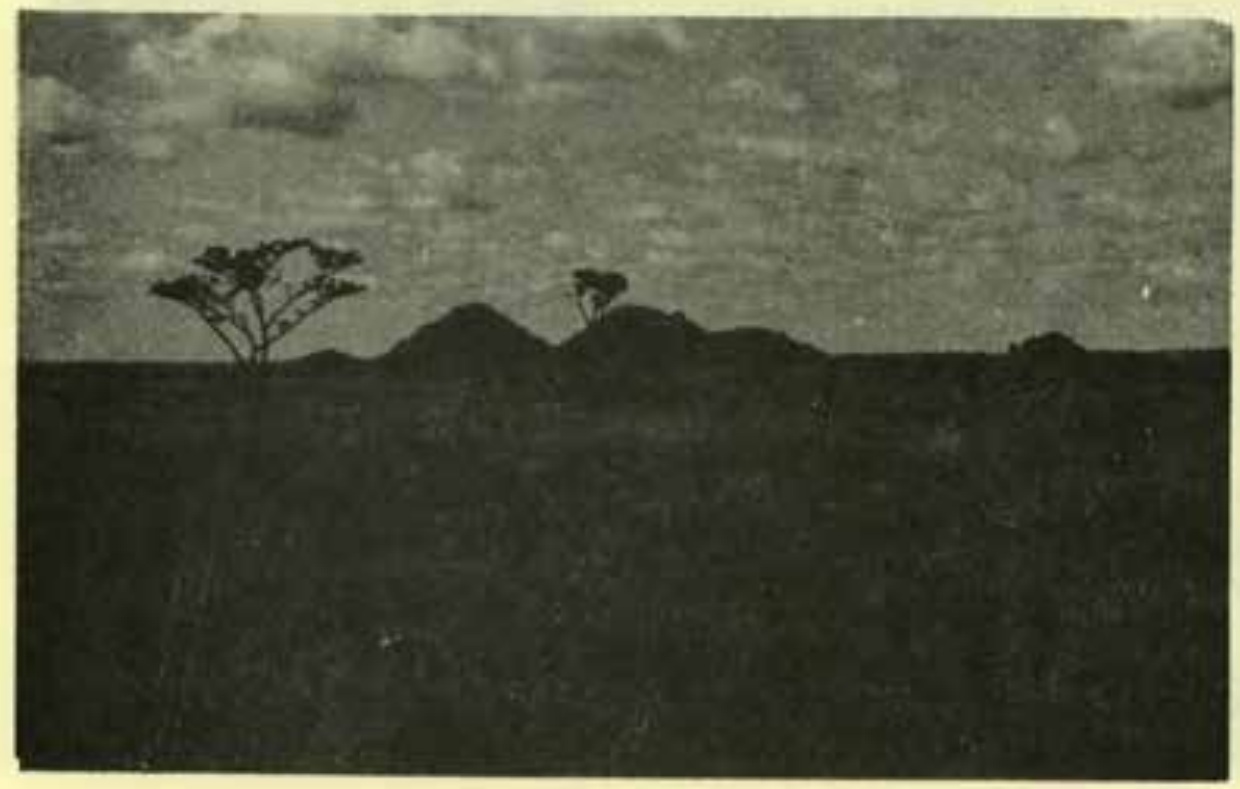

Lámina XI. Zona central de Santa Clara, sitio enclavado sobre la margen izauierda del Caribe.

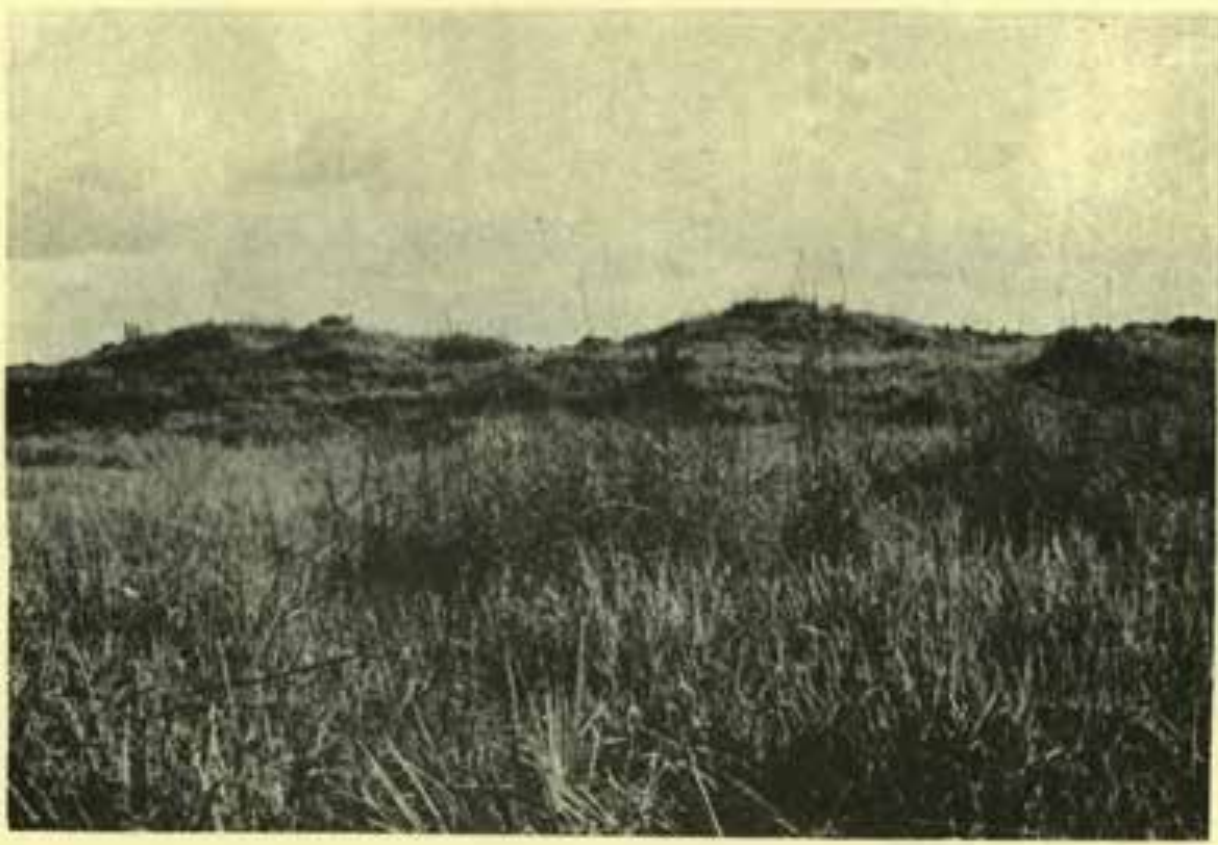

Límina XII Sección suroeste de la zona central de Santa Clara. 


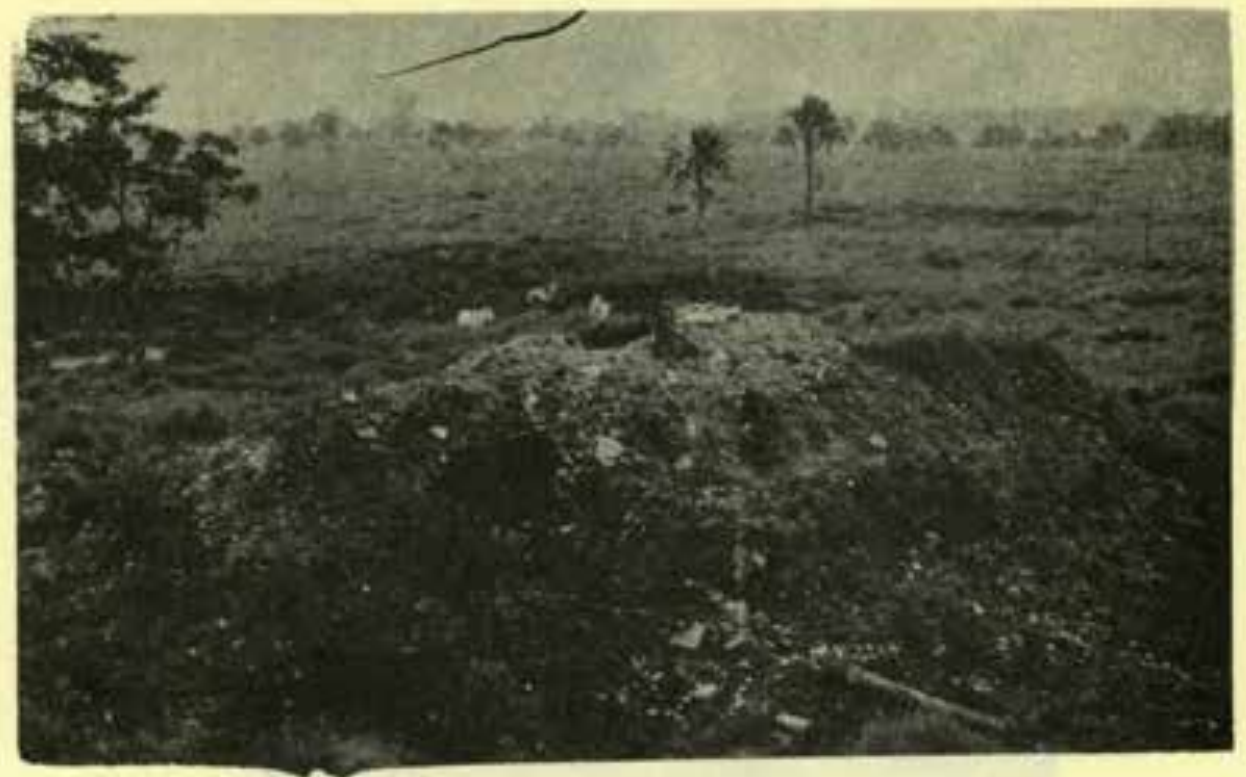

Limina XIII. Edificio saqueado en el sitio La Rancheria.

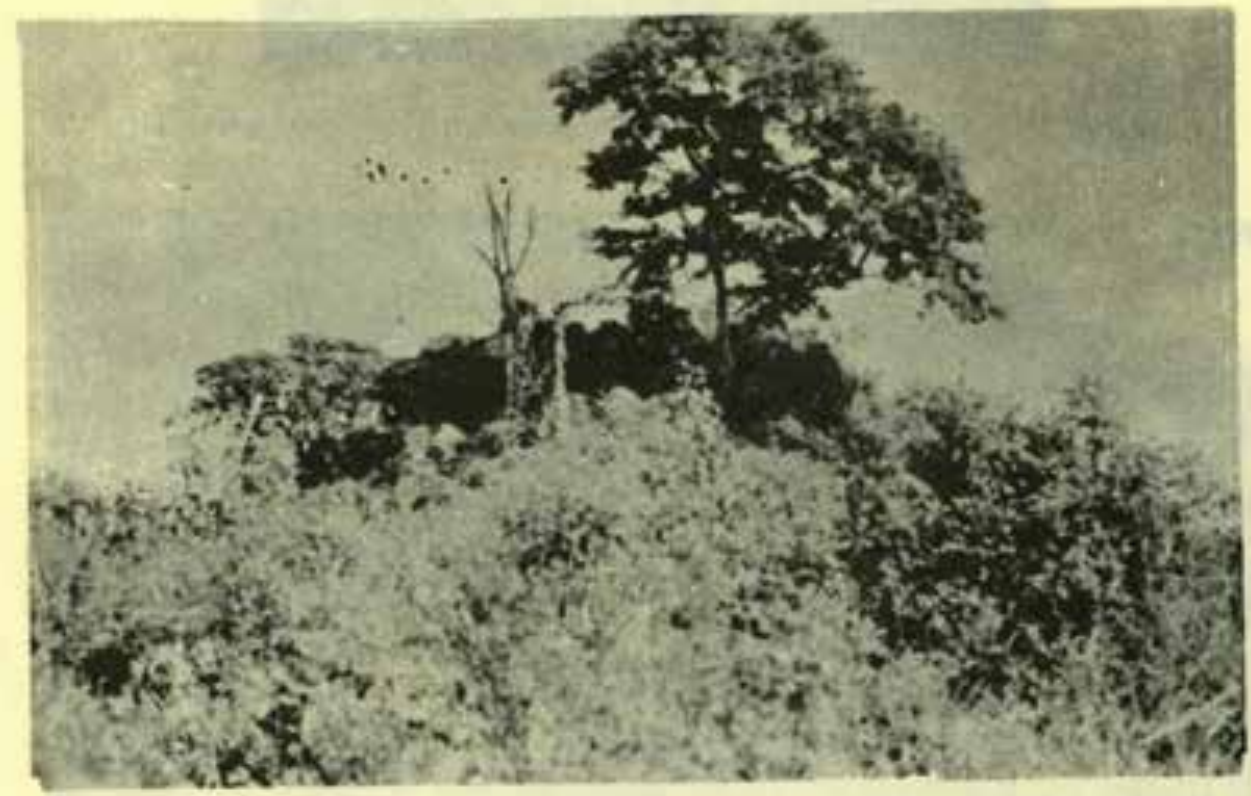

Límina XIV. Monticulo del sitio de Las Pezas. 


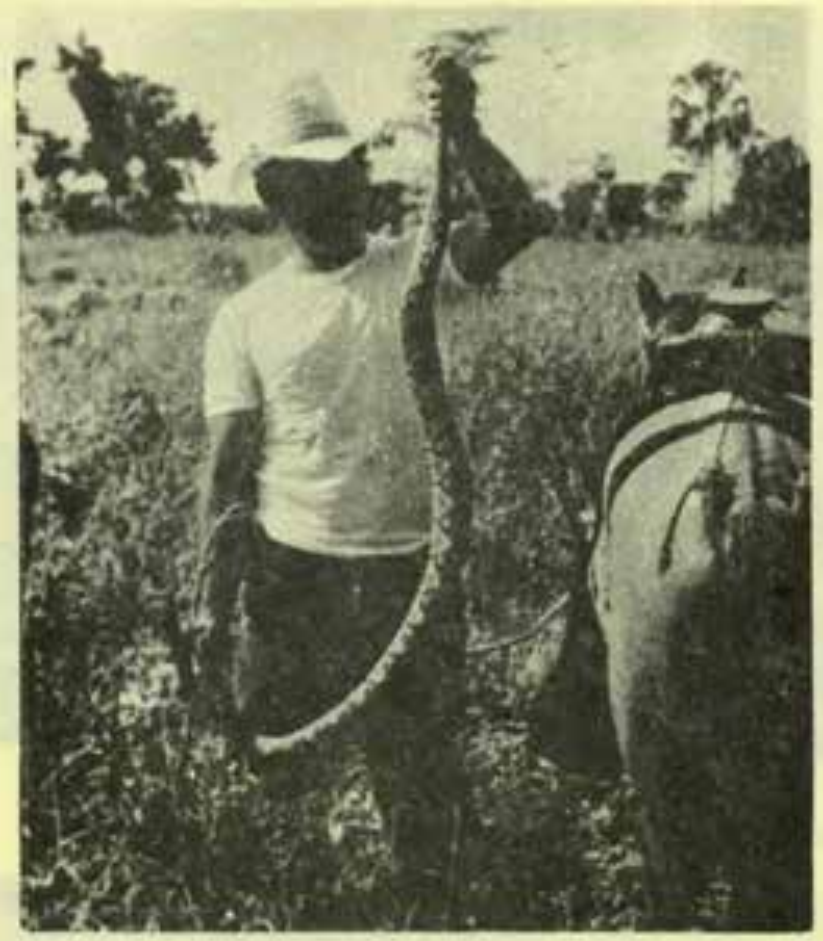

L.ámina XV. Vibora de cascabel muerta durante el recorrido hacia EI Zarzal.

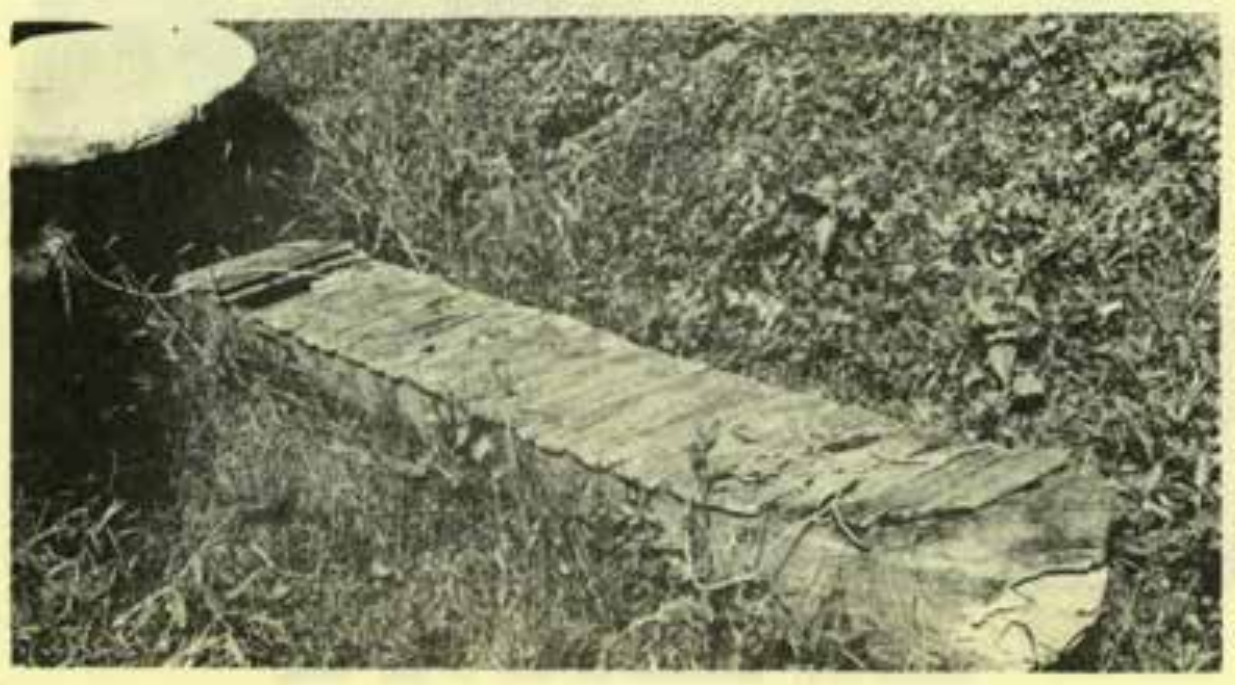

Lamena XVI, Irampa para alracenar peces con el propónito de mantenerlos vivos. 


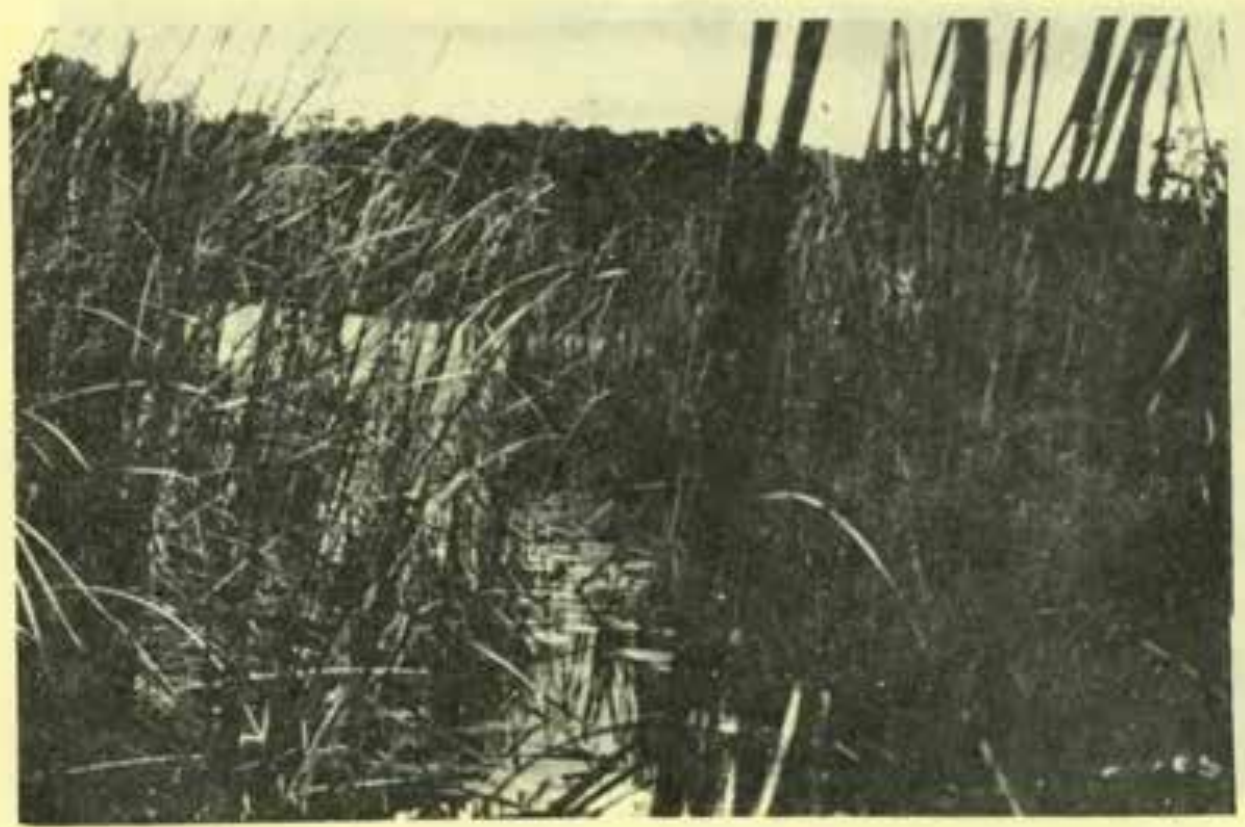

Lamina XVIL. Salida al rio Candelaria per el canal de EI Chilar, prohablemente ccnstruido a finalea del siglo XIX o a principios de bite.

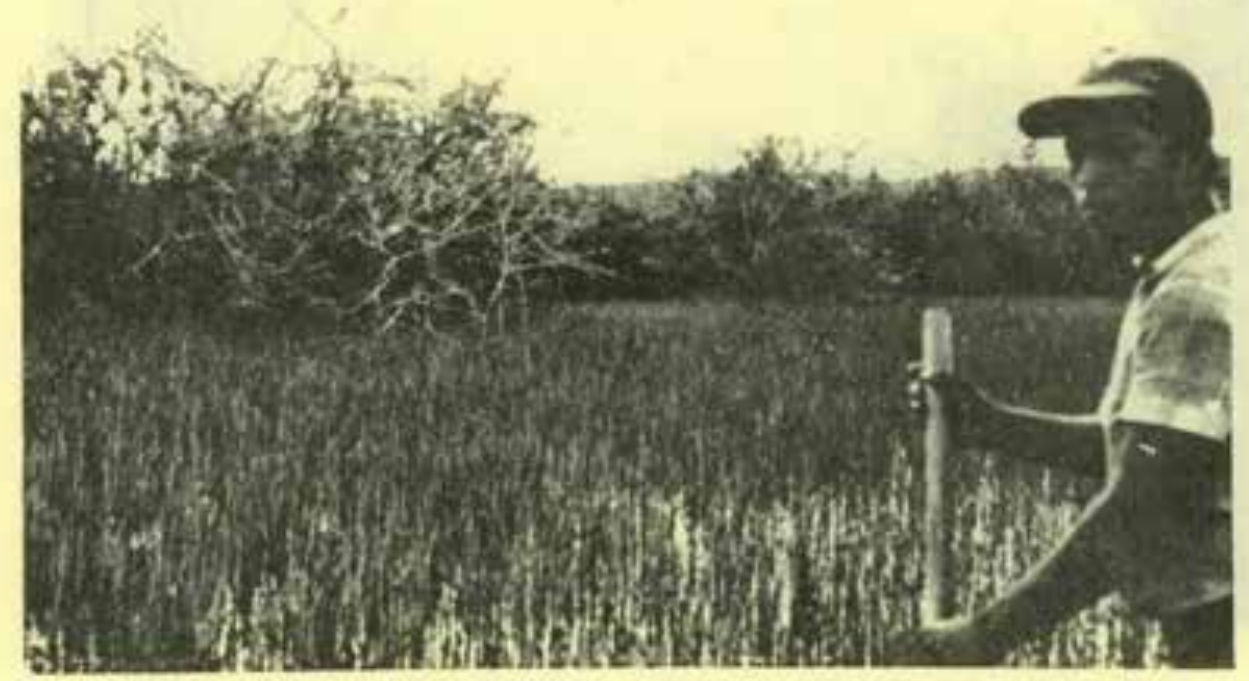

L.simina XVIII. Navegación entre los camellores localizador sobre la thasgen derecha del Candelaria después de la época de lluvias. 


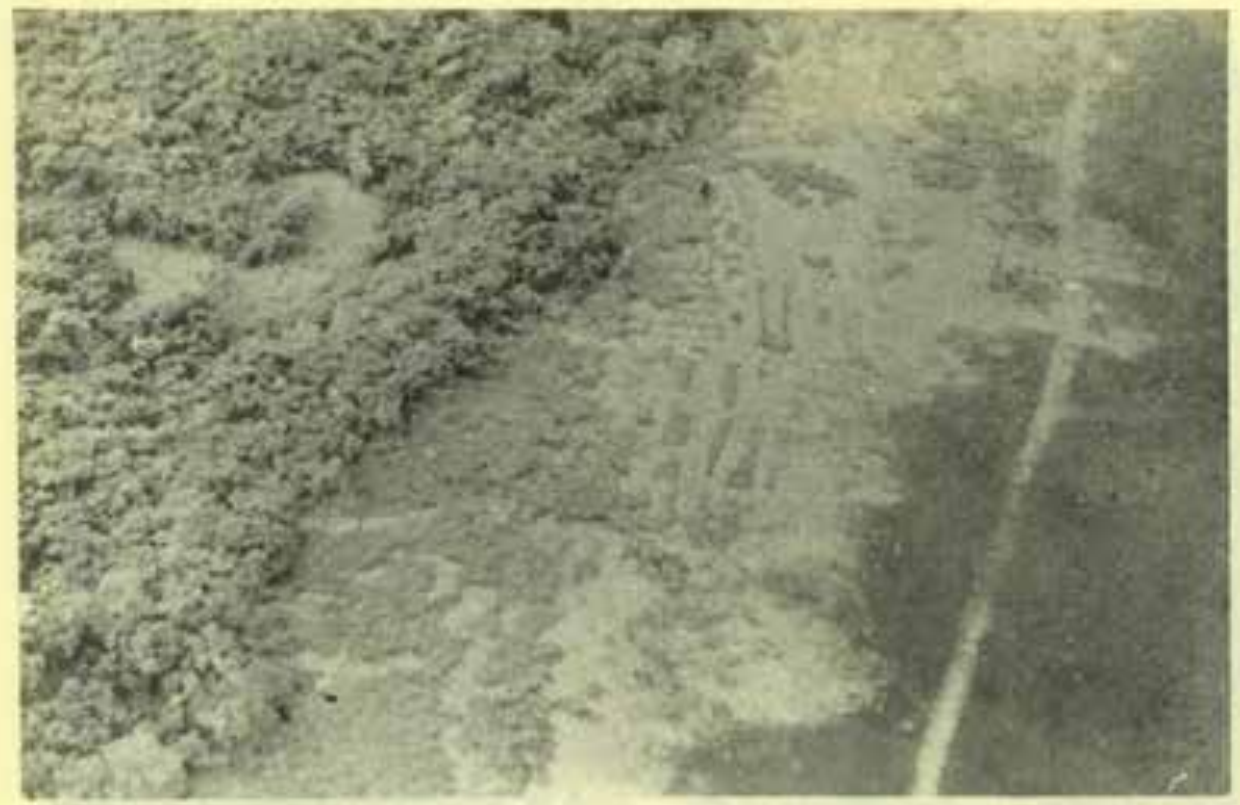

Lámina XIX. Vista aérea de los supueston camellones de cultuvo despouts de la época de lluvias. La línea elara corresponde a un sendero marcado por el ganado scbre la margen izquierda del Candelaria.

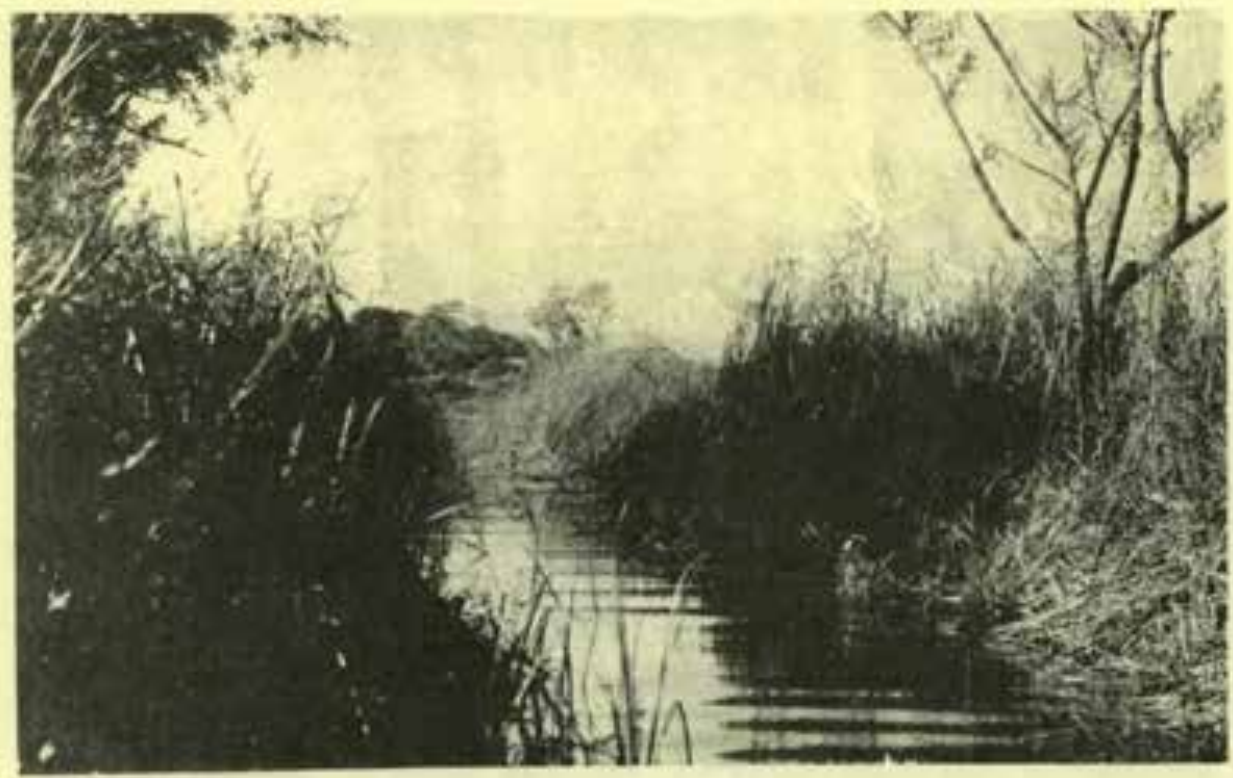

Limina XX. "Canal" que habia sido abierto recientemente antea de nuestro reconocimiento y que conduce a un rancho localizado so: bre la margen iequicrda del Candelaria. 


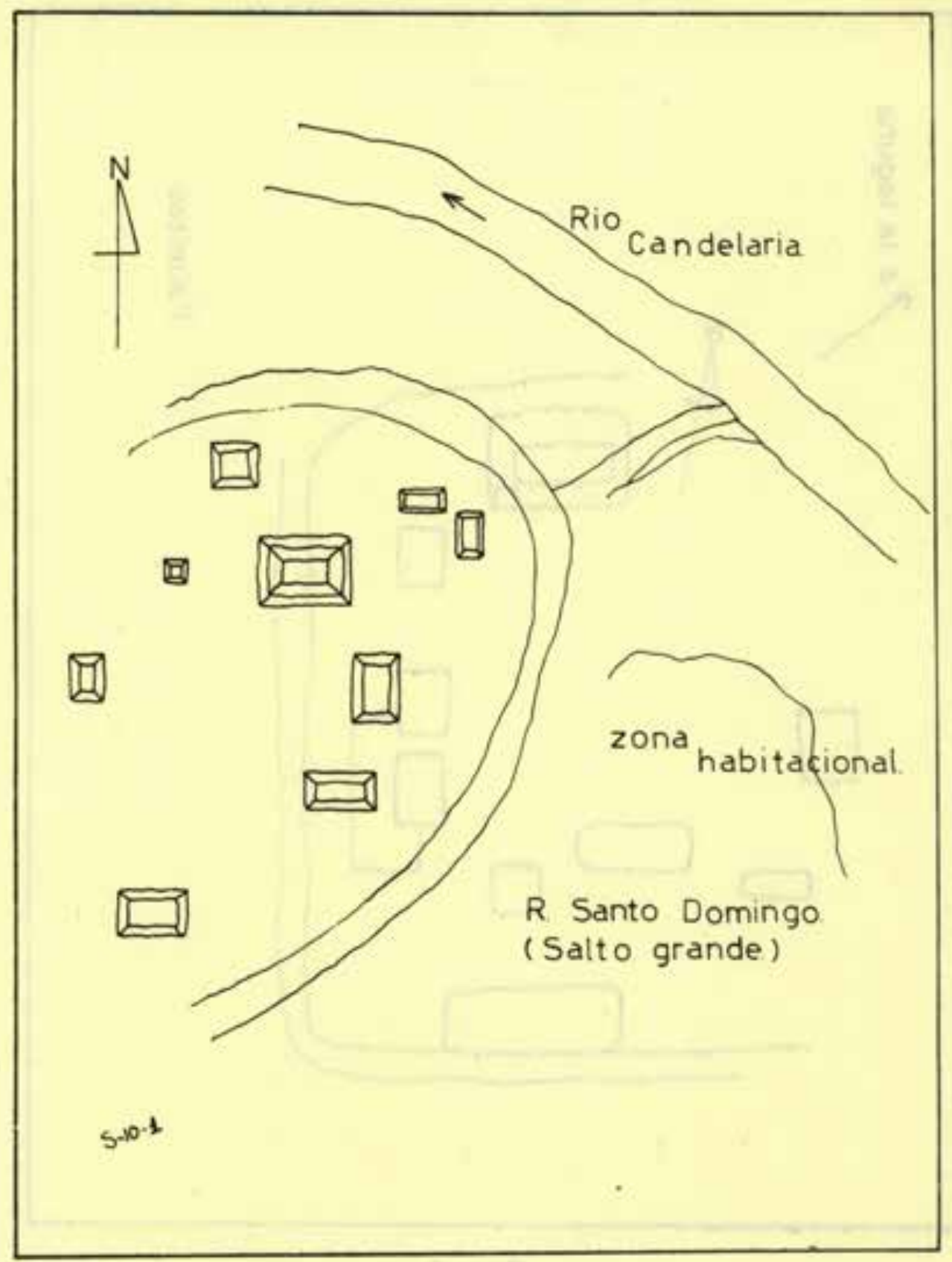

Figura 1: 


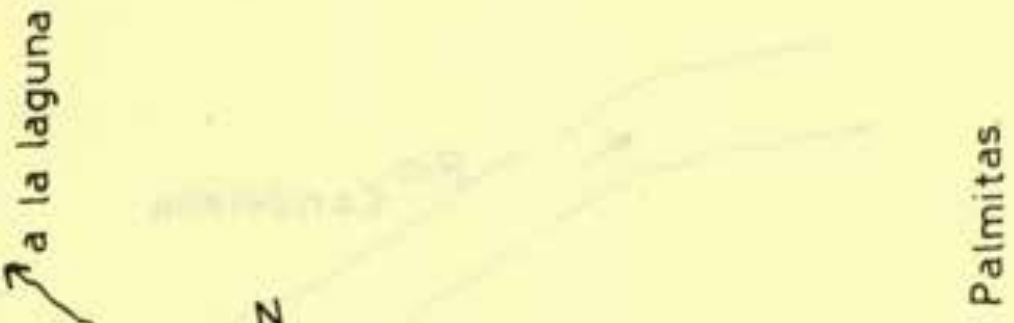

$\square$
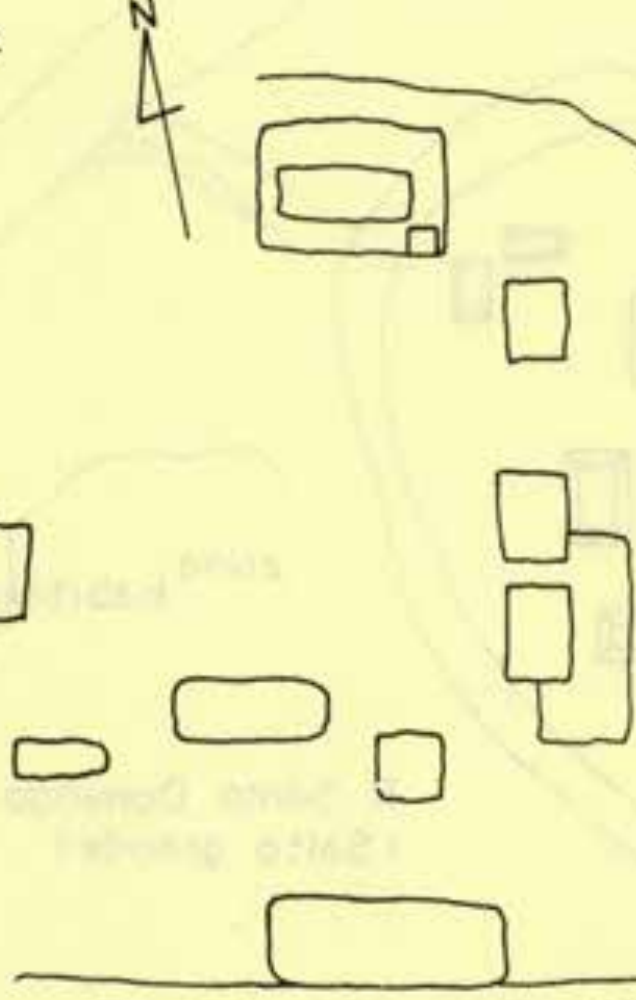

Figura ? 

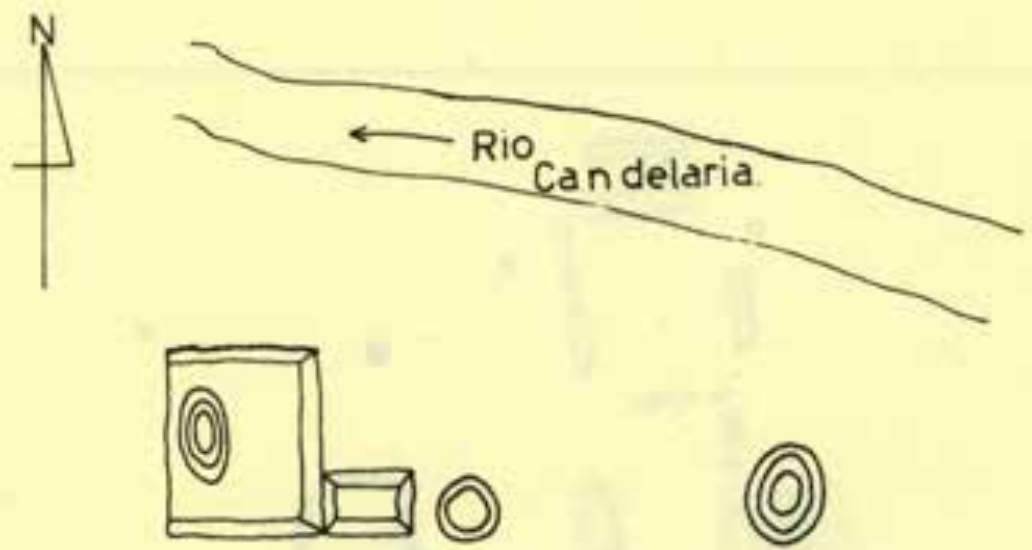

(0)
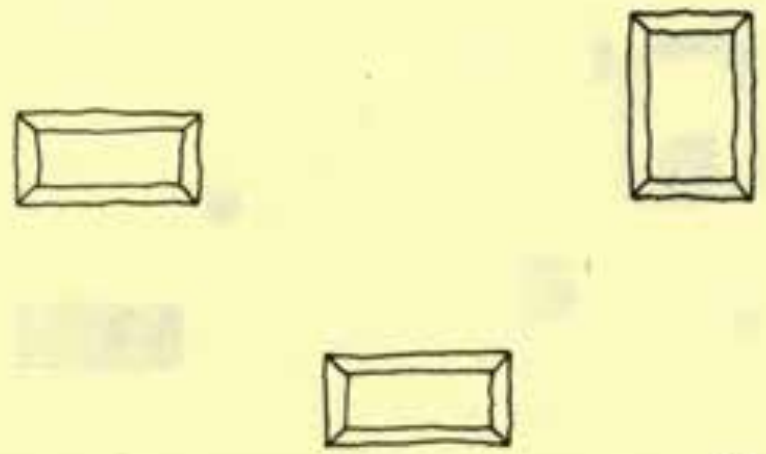

Rancho

(O) (El Naranjal.)

Figura 3 


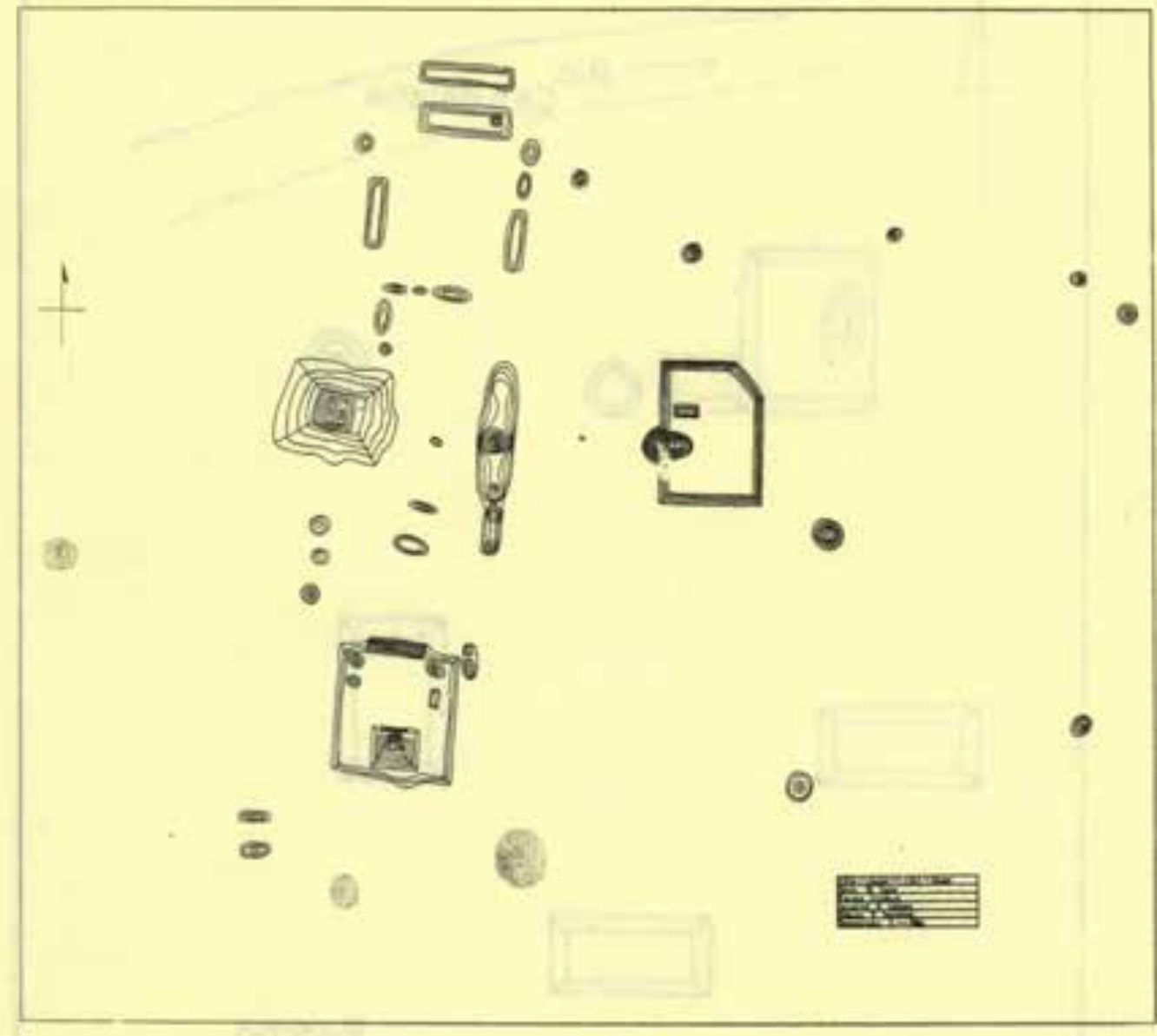

Figura 4 

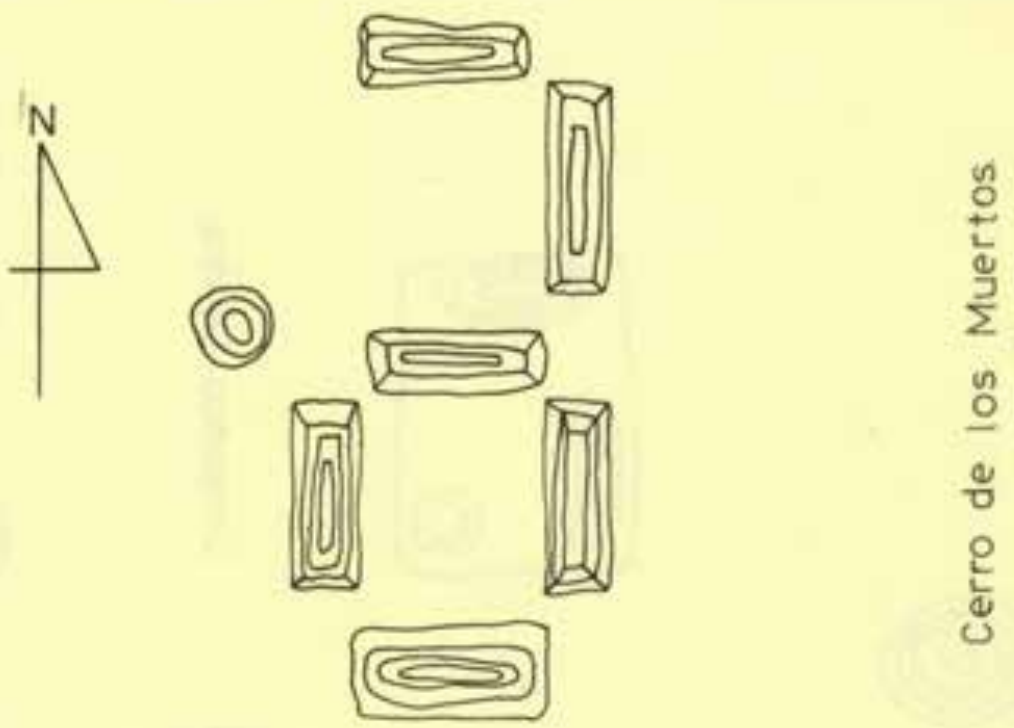

(2)

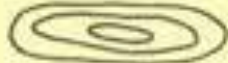

(2)
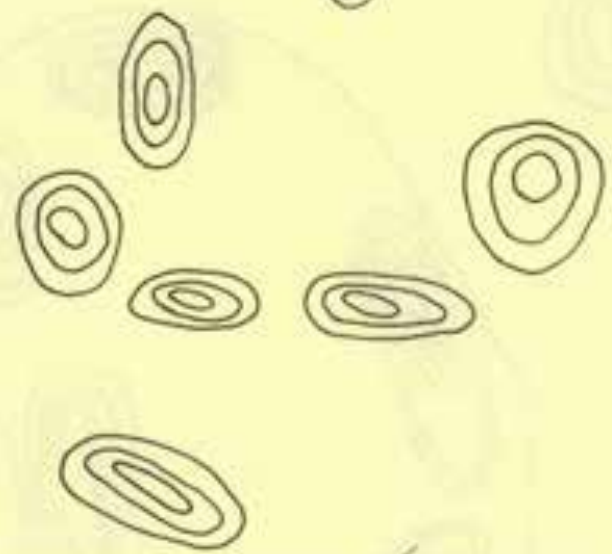

Figura 5 


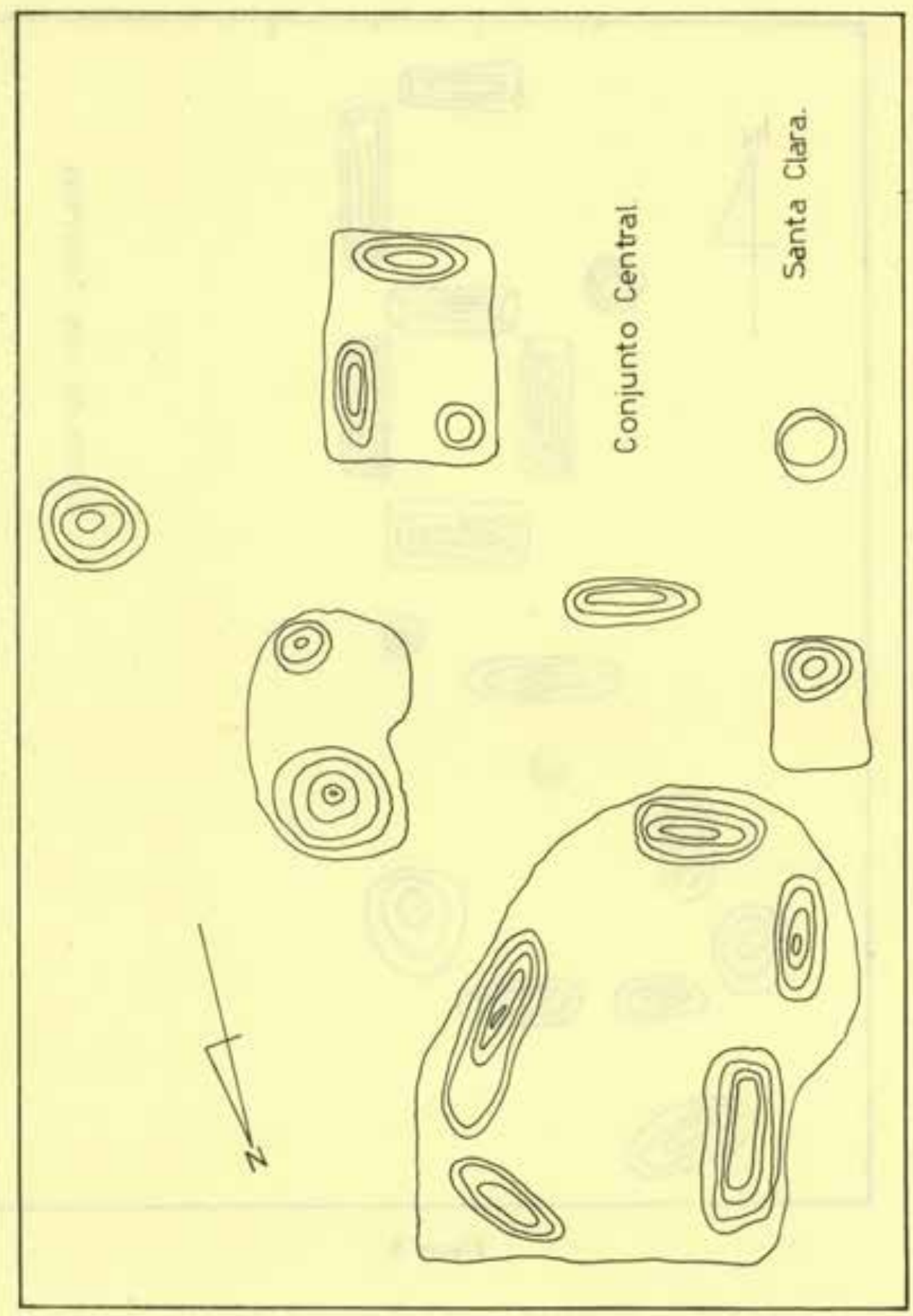

Figura 6 . 


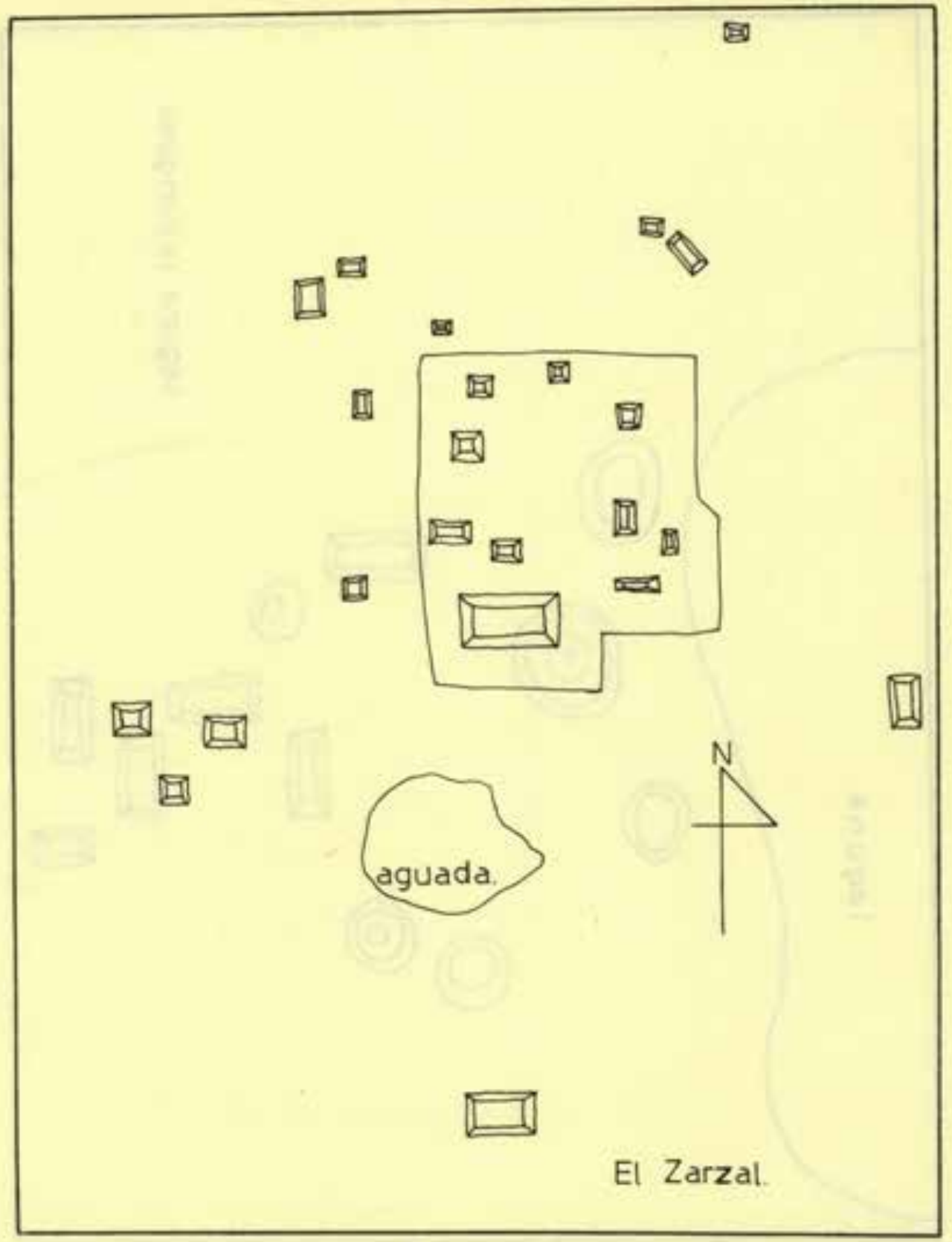

Figura ? 


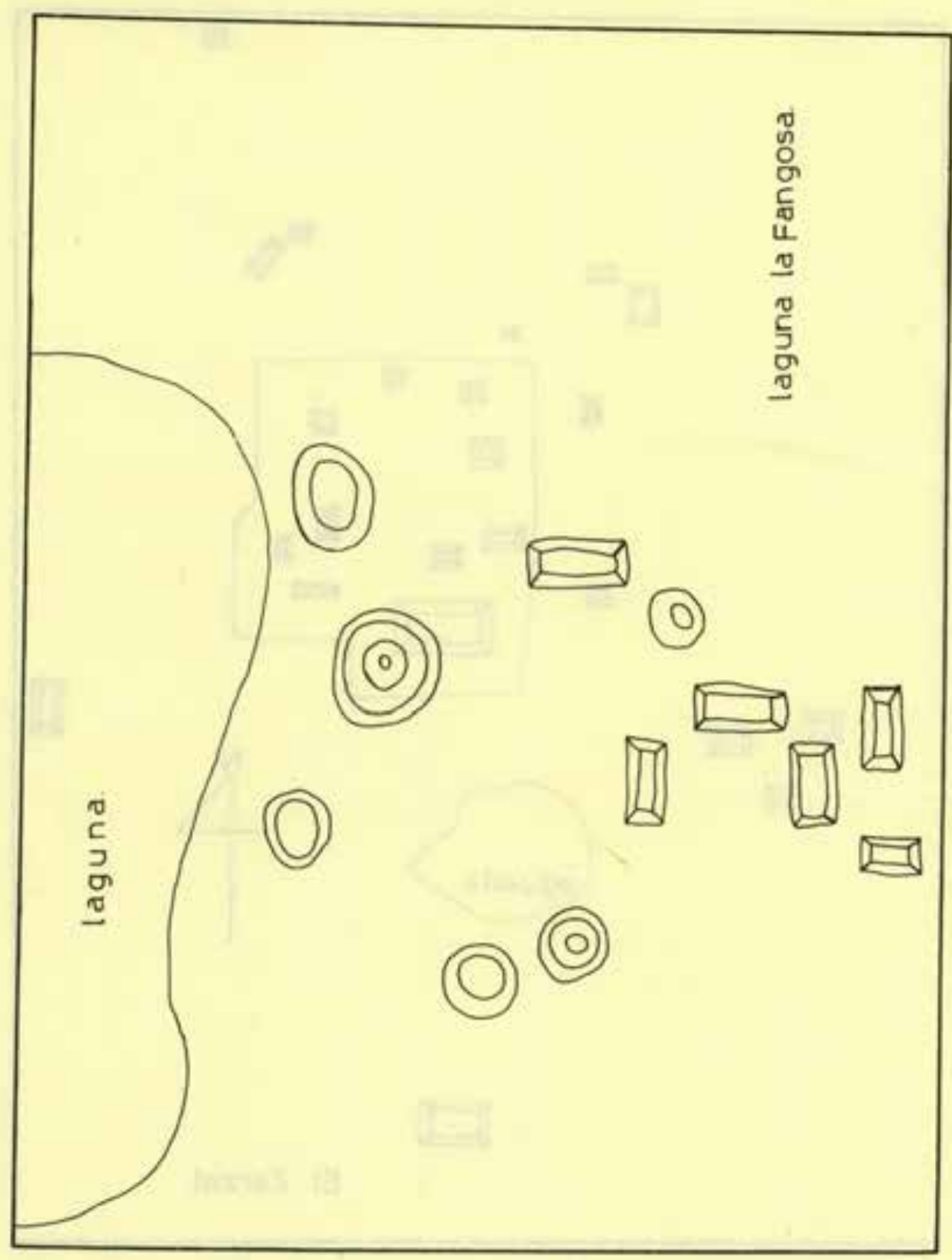

Figura 8 


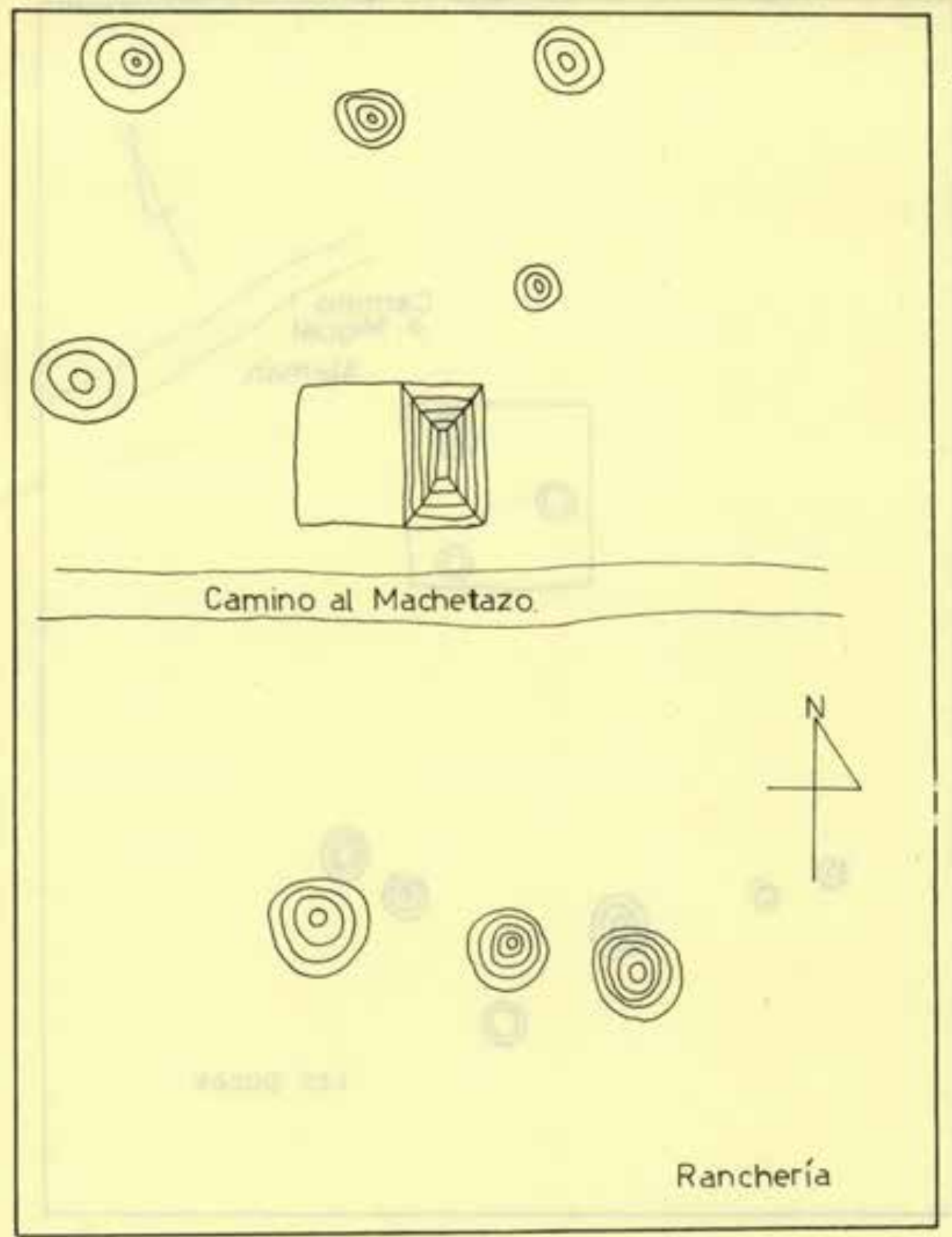

Figura 9 


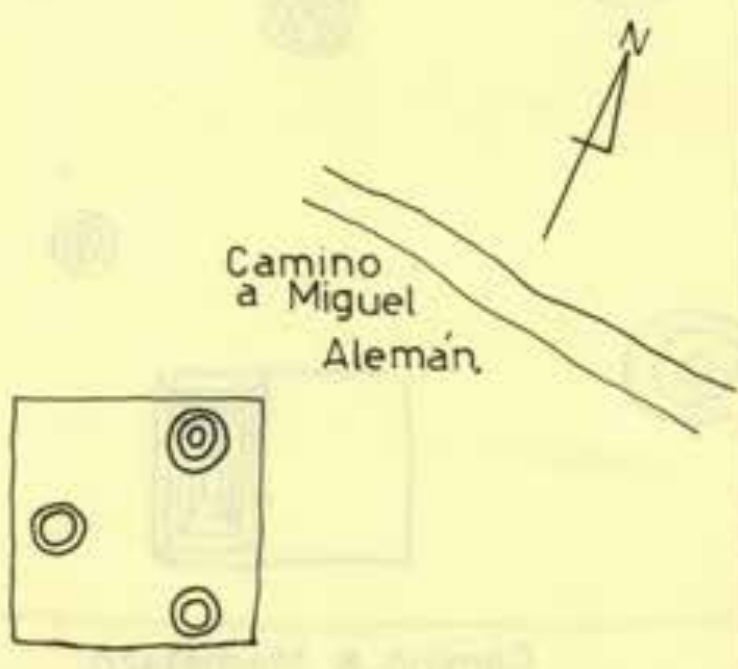

(อ)

(.)

(0)

())

(Q)

(2)

las pozas

Figura 10 

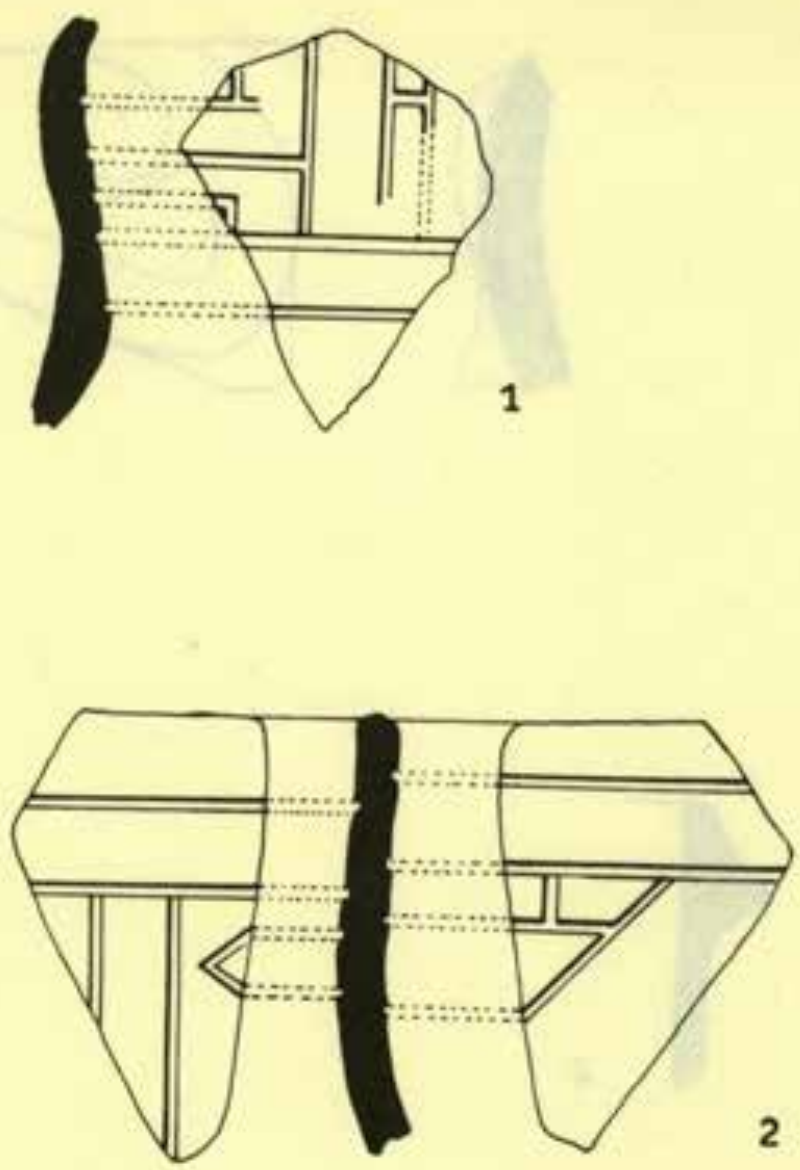

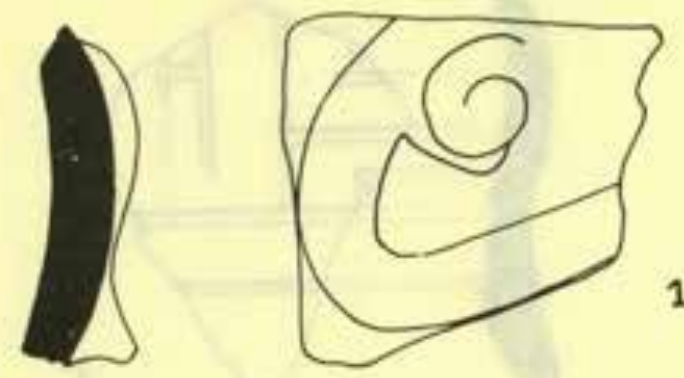

1
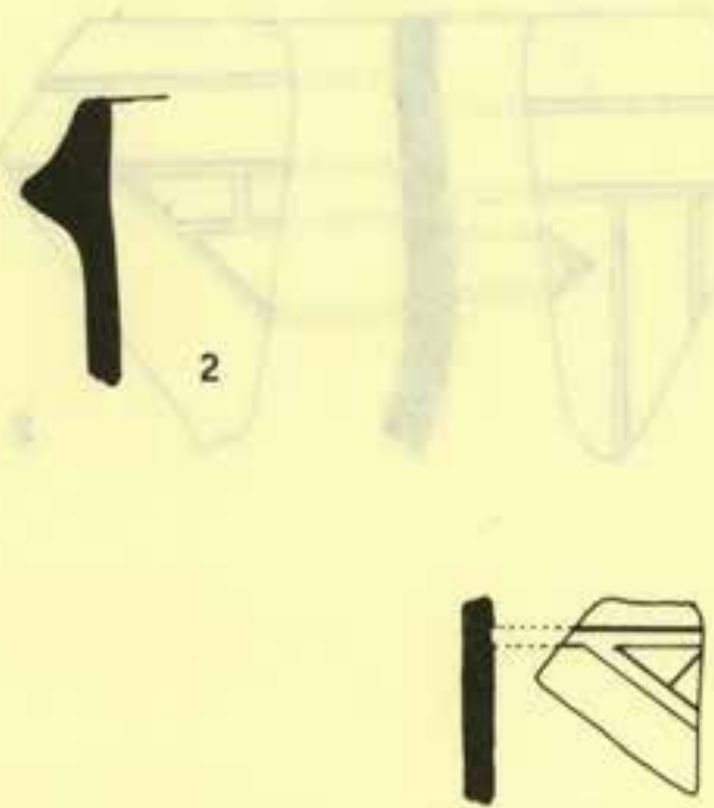

4

$1,2,3$

SAN RON:AN

4

SANTA CLARA

Figura 12 


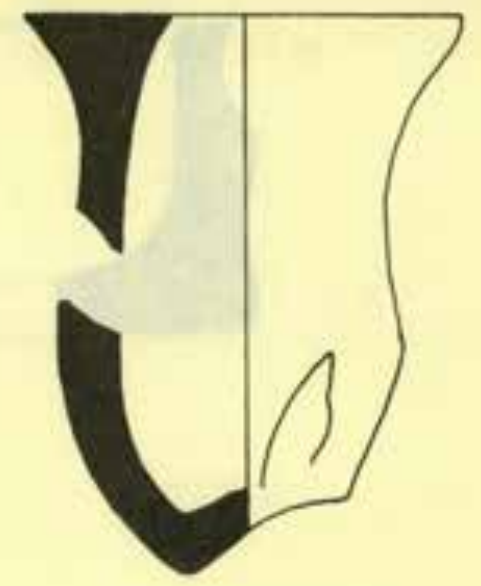

1

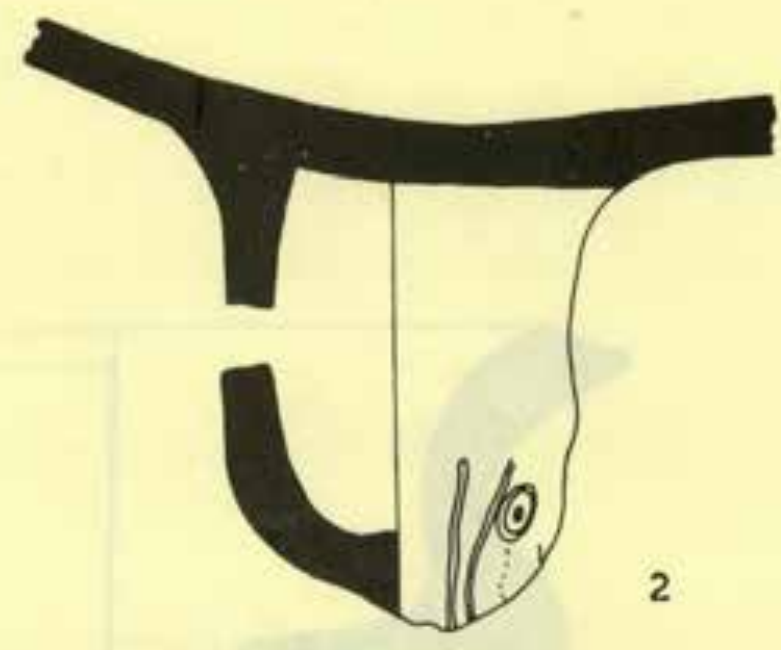

Cuamica anaranjada fina (Matillas) de 1, SANTa Clara

2, RANCHO EL LIMON

Figura 13 
